\title{
About the Respective Roles of Central and Intraorgan Nervous Systems in Regulation of the Gastrointestinal Tract Physiology and Morphology
}

Coulic V', Mikhalsky DV², DePrez $\mathrm{C}^{3}$, lesuitova NN ${ }^{4}$, Makarova LF ${ }^{5}$, Maksimenkova AN ${ }^{5}$, Delrée $\mathrm{P}^{6}$

${ }^{1}$ Laboratory of Experimental Medicine, Free Brussels University, Brussels, Belgium

${ }^{2} \mathrm{CHU}$ Erasme, Free Brussels University, Brussels, Belgium

${ }^{3}$ Laboratory of Pathology, CHU Brugmann, Brussels, Belgium

${ }^{4}$ Laboratory of Nutrition Physiology, Academy of Sciences, Cankt Petersburg, Russia

${ }^{5}$ Laboratory of Organ and Tissue transplantation of the USSR Academy of Medicine, Moscow, Russia

${ }^{6} I P G$, Gosselies, Belgium

\section{Abstract}

The role played by central nervous system in the general regulation and coordination of organ, tissue and even cell activities does not stop to excite the curiosity of investigators. Recently important data were obtained in the field of new neurotransmitters and other active molecules which mechanisms of actions and interactions were clarified. But the function of intra organ, local nervous system, its relations with the main brain and medullar centers remain a little enigmatic though much is known about tiny paths of afferent, efferent and inter neuronal transmission.

In order to isolate the influence of central and intramural nervous system of the intestine, several situations were considered: 1) surgical interruption of nervous reflex links (NRI), which is always present in organ transplantation and often occurs in spinal cord trauma, 2) injury of the intramural nervous system with perfectly conserved links with central nervous system, for instance after intestinal ischemia and in Hirschprung disease. As control a technique of surgical directed re innervation (SDR) of the intestinal graft by suture of the divided mesenteric plexus was elaborated. A model of ontogenetic reconstruction of adult-like organs after syngeneic implantation into an adult organism of a fetal organ containing (intestine) or not (liver, pancreas) an organized intramural nervous system, was also used.

The experiences on 101 dogs and 300 rats and 25 mice were conducted by the same team according to the rules of Bioethics.

Performed investigations concerned testing nervous connection with central nervous system (Recto-enteric reflex presence, normal reaction to anticholinergic substance), evaluation of motility, secretion, membrane digestion of the intestine, as well as optic and electron microscopy of the target organs.

The results may be summarized as following.

Disconnection from the CNS does not significantly affect more than a few days (influence of operation trauma) the intrinsic functions and the morphology of the intestine but has an incidence on the own rhythm of the organ activity which becomes "autonomous" and stops to be integrated into the whole regulation of digestive tract function. It creates such disorders as accelerated nutrient transit, hyper secretion, body weight loss. The activity of the remaining linked with central nervous system stomach and colon is modified in such a way that final digestive process is adapted and correctly realized (central nervous coordinating intervention). Restoration of central nervous reflex control of the operated intestine leads to the normalization of its activity and of the whole digestive process.

The destruction of intramural nervous system either by prolonged ischemia, or by congenital dysplasia affects both function and morphology of the intestine. The ontogenetic complete development of a grafted fetal organ is possible only when it presents an intramural nervous system (for instance, intestine). If intra organ neurons are not organized as plexus, the graft development is partial and not coordinated: only isolated weakly organized structures develop (for instance in the ectopically grown fetal liver - bile ducts, hepatocytes column, in pancreas - endocrine cells isolated or in clusters), without any links between each other.

These findings may be interesting for the development of organ transplantation, when it may be useful to restore not only the vascular connections of the graft with the host, but also the nervous links of the transplant with the recipient central nervous system (brain and spinal medulla). This conception may be worthwhile in the treatment of such pathology as digestive difficulties in tetra and paraplegia patients on one side, of Hirschprung disease on the other side. It may also help to consider and understand the problems which may be either the consequences of central nervous system alterations for digestion or, on the contrary, the incidence of severe peripheral disorders for the brain activity.

Keywords: Intra mural nervous system; Central nervous system; Organ transplantation; Nervous regulation; Intestine physiology and morphology; Nervous and humoural regulation

Abbreviations: NRI: Nervous Reflex Interruption/isolation; Tx: Transplantation; OTx: Orthotopic Transplantation; HTx: Heterotopic Transplantation; SDR: Surgically Directed Re Innervation; Ctrl: Control; CNS: Central Nervous System; INS Intramural Nervous System; BW: Body Weight; GFP: Green Fluorescent Protein; M: Mean vaues; SD: Standard Deviation
*Corresponding author: Very Coulic, Universite Libre de Bruxelles, Bruxelles, Belgium, Tel: 32247725 74; E-mail: verycoulic@gmail.com

Received March 22, 2015; Accepted June 20, 2015; Published June 26, 2015

Citation: Coulic V, Mikhalsky DV, DePrez C, Delree P, lesuitova NN, et al. (2015) About the Respective Roles of Central and Intraorgan Nervous Systems in Regulation of the Gastrointestinal Tract Physiology and Morphology. Brain Disord Ther 4:172. doi:10.4172/2168-975X.1000172

Copyright: $\odot 2015$ Coulic V, et al. This is an open-access article distributed under the terms of the Creative Commons Attribution License, which permits unrestricted use, distribution, and reproduction in any medium, provided the original author and source are credited. 


\section{Introduction}

The intra mural plexuses of the digestive tract organs have been known since the end of the $19^{\text {th }}$ century $[1,2]$. Ph.Stöhr $/ 1952 /$ considered it as "a part of the central nervous system transferred to periphery" [3].

At the beginning of the $20^{\text {th }}$ century the experiences of Nobel Prize Academician I.P.Pavlov on the conditioned reflexes have convinced that central nervous system plays a capital role in the regulation of different digestive functions [4].

All through the $20^{\text {th }}$ century up to the last years, mechanisms of nervous transmission, role of neurotransmitters, interactions between organ cells and neurons, as well as interaction between neurons themselves at different levels of the nervous system were elucidated (for instance: discovery of neurotrophic factors, precision of the role of Cajal cells and so on [5-7]). At least in vitro cultures of neurons obtained from stem and precursor cells have allowed pointed studies about molecular biology of the nervous system and its activities [8-11].

Despite the general successful tendency to investigate deep intracellular structures and functions up to the molecular level for seeking explanation to problems, some questions may still be discussed in terms of macro- and microscopic studies. For instance, in the digestive tract the respective roles of central and intramural innervations remain not quite clear [12]. That may have consequences for the treatment of several digestive pathologies.

The development of adult organ transplantation has given unique opportunity to study separately the influence on the morphology and the physiology of the grafts of different factors: ischemia, interruption of nervous and lymphatic links with the host. The impact of these factors on the graft condition was studied but more for practical measures ensuring immediate success: for instance determination of warm and cold ischemia duration compatible with graft and recipient survival [13-15]. Few authors have directed their attention to the graft physiology at late observation delays and related their findings to the nervous connection alteration due to the grafting [16-18].

As to the specific role of intramural nervous system in conditioning intestinal function and morphology, Hirschprung's disease being considered as an intestinal neuropathy with muscular dysfunction [19] constitutes an interesting investigation model. Traumatic interruption of the spine cord, i.e. of the central nervous communications with the gastro intestinal tract, also leads to severe functional alterations of the digestive system [20,21]. The management of these pathologies is also very difficult up to now and includes trials with local implantation of nerves or neurons [22-24].

On another side many previous observations have shown that fetal intestine and stomach implanted in an ectopic site of adult organism are able to develop and to become morphologically mature and functional [25-27]. But the influence of the presence of intra organ neurons on the implant function and morphology or the situation of the implant own intramural plexus relatively to the host nervous system was not investigated.

So the purpose of the present work was to study and to compare different models of digestive organs innervation alterations both at the central level of nervous communication and at the peripheral one (intramural nervous system) to determine their influence on the functional capacity and morphological integrity of the intestine. The integration of the obtained results might allow a better understanding of the possible mechanisms of central and peripheral innervations regulating gastro-intestinal tract physiology and morphology, in order to approach possible clinical applications.

\section{Materials and Investigation Methods}

The experiments were conducted on 101 mongrel dogs of 12-15 kg BW, 300 rats Wistar and Fischer, males and females (Table 1). Here are considered only animals having survived and observed during a determined period after surgery.

25 C53Bl "Wild" and GFP (green fluorescent protein) marked mice were also used in order to try an identification of the recipient GFP material included within the "wild" implant growing in a GFP marked adult mouse (generous gift from Ulg Hematology Laboratory, Belgium).

Animals were managed before, during and after operation or investigations according to the Helsinki Convention (1975) and after year 2000 also according to protocols agreed by local Bioethics Committee.

\section{Surgical methods}

In dogs: All the animals were given an induction anaesthesia (subcutaneous injection of a $1 \%$ Morphine solution, $0.5 \mathrm{ml} / \mathrm{kg} \mathrm{BW}$ ) followed by intravenous injection of Thiopental Sodium (1\% solution titrated according to the disappearance of the eyebrow reflex). After surgery analgesia was provided during 1 or 2 days by subcutaneous injection of $1 \%$ solution of Promedol (P) (similar to Paracetamol) $2 \mathrm{ml}$.

In all the cases operations began after preparation (washing, shaving and disinfection of the anterior abdominal wall). Incision of the abdominal wall following the middle white line from sternum xiphoid appendix to the pubis was provided; small bowel was mobilized and put into a plastic bag to avoid desiccation. Then one of the following surgical protocols was applied:

Autotransplantation (Tx) - The small bowel was separated from the colon and divided at the level of colico-duodenal ligament and at 10 $\mathrm{cm}$ of the Bauhin's ileocaecal valve in such way that it remains attached to the host by the mesenteric vascular and nervous bundle (Figure 1a). After what in the case of orthotopic autotransplantation (OTx), this bundle was cut and the continuity of the mesenteric artery and vein was restored by vascular sutures of the cut edges of the mesenteric vessels (running $5^{\circ \circ}$ and $6^{\circ \circ}$ Ethicon).

In the case of heterotopic autotransplantation (HTx), the proximal edge of anterior mesenteric vessels was ligatured, the right iliac vessels were mobilized and cut, their proximal edge was sutured to the open edge of the transplant vessels. Ischemia duration was always less than $50 \mathrm{~min}$. After what the mesentery was sutured and reinforced by nylon net. The intestinal continuity was restored by an end to end double layer suture with sub mucous running, and serous separate stitches (Figure $1 b)$.

In the case of neuroreflex isolation (NRI), after standard "isolation" of the small bowel like in OTx, the mesentery and its plexus was accurately divided and the vessel walls washed with a $5 \%$ alcohol/iodine solution in order to destroy their adventitial nerves. It is to be noted that no ischemia of the small bowel may occur (Figure 1c).

Orthotopic surgical directed reinnervation (SDR) was performed by suturing the cut edges of divided mesentery (after NRI or OTx) with para and epineural stitches on the main nervous trunks (Figure 1d).

In the case of heterotopic SDR the sacral plexus (containing at this 


\begin{tabular}{|c|c|c|c|c|}
\hline & Animals & number & $\begin{array}{c}\text { Observation } \\
\text { delay } \\
\text { (months) }\end{array}$ & Remarks \\
\hline Small bowel NRI & dogs & 12 & Up to 18 & \\
\hline Small bowel NRI+SDR & dogs & 12 & Up to 12 & \\
\hline Small bowel OTx & dogs & 12 & Up to 24 & \\
\hline Small bowel OTx+SDR & dogs & 12 & Up to 18 & \\
\hline Small bowel HTx & dogs & 12 & Up to 24 & \\
\hline Small bowel HTx+SDR & dogs & 12 & Up to 18 & \\
\hline Small bowel ischemia & dogs & 12 & Up to 16 & \\
\hline Control 1 (intact) & dogs & 5 & & Only general condition \\
\hline $\begin{array}{l}\text { Control } 2 \text { (Thirry-Vella loop } \\
\text { from intact bowel) }\end{array}$ & dogs & 12 & & + in all series loop from intact bowel \\
\hline Small bowel NRI & rats & 17 & $0,25-0,5-1-3$ & \multirow{7}{*}{34 with STZ DM } \\
\hline Control 1 (intact) & rats & 17 & 0 & \\
\hline Control 2 (laparotomy) & rats & 16 & $0,25-0,5-1-3$ & \\
\hline $\begin{array}{l}\text { Fetal bowel/stomach } \\
\text { implant }\end{array}$ & rats & 102 & Up to 12 & \\
\hline Fetal pancreas implant & rats & 98 & Up to 18 & \\
\hline Fetal liver implant & rats & 50 & Up to 12 & \\
\hline Fetal intestine implant & mice & 25 & Up to 6 & \\
\hline
\end{tabular}

Table 1: Experimental series.

level parasympathetic fibres and neurons from the sacral medullar parasympathetic nuclei, as well as sympathetic nerves) was divided and a flap of it was sutured, as described above, to the edge of the mesenteric plexus of the graft (Figure 1e).

In the series with temporary ischemia of the small bowel, after isolation of the major part of the small bowel as described above, clamps were placed on the proximal and distal extremities of the isolated segment (to prevent blood exchanges through vascular arcades and through intramural vessels), clamps were also placed first on the mesenteric artery then vein of the isolated intestine (Figure 1f). Criteria for complete blood supply interruption were white colour of the intestine and absence of peristalsis in it. All the clamps were released within no less than 50 minutes, the intestinal transit again ensured. It is to be noted that no injury to the mesenteric plexus was provided.

For investigations of the secretion and motility functions of the small bowel a $15 \mathrm{~cm}$ long loop was isolated by Thirry-Vella method on both parts - intact and operated - of the small bowel (Figure 1a and $1 b)$. It is known, that functions of these loops reflect functions of the whole intestine [28].

In control group, for testing the influence of operation trauma, sham operation consisted in isolation of an intestinal loop from the jejunum according to the Thirry-Vella technique.

All the operations ended by suture of abdominal wall in three layers: running catgut $3^{\circ \circ}$ on the peritoneum, separated silk or Vicryl stitches $2^{\circ \circ}$ on the white line and on the skin.

In rats: NRI operation similar to the dog's one was also elaborated in order to test membrane digestion. The difference consisted in inclusion of the caecum and a part of ascending colon into the graft because of anatomic peculiarities of the proximal mesenteric artery in rats (Figure $1 \mathrm{~g}$ ), and in the size of suture material used: $4^{\circ \circ}$ for abdominal wall and $6^{\circ \circ}$ for bowel end to end one layer anastomosis.

The main model of rat and mouse operations was syngeneic (to avoid rejection problems) fetal organ implantation (Figure $1 \mathrm{~h}$ ). Grafts were taken out of foetuses aged 16-19 days after euthanasia of the mother by Nembutal overdose (intra peritoneal injection of $1 \mathrm{ml}$ of $0.1 \%$ solution), that ensured anaesthesia of the donor too. Implantation was carried on adults of the same strain under gas (Isofurane 5\%, 1 $\mathrm{min} / 100 \mathrm{~g} \mathrm{BW}$ ) only or with complementary intra peritoneal Nembutal injection (0.75\% - $0.5 \mathrm{ml} / 100 \mathrm{~g} \mathrm{BW})$. After alcohol $80 \%$ disinfection subcutaneous pouch was managed in the ear pavilion and the intestinal segment introduced. The duration of the period between isolation and implantation of the graft did not excess 40-50 min. The edges of the wound were closed either by a slight pressure, or by Nobecutane (P) drop. For implantation, fetal Intestine and stomach - as having a well-developed intramural nervous system, fetal pancreas and liver as organs with only dispersed neurons, were used. The same model of small bowel implantation at the site ear was used in GFP mice with adapted anaesthesia

\section{Investigation methods}

This concerned both physiology and morphology of target organs:

In dogs: The proofs of nervous links interruption and restoration between organ and CNS were obtained by determination of rectoenteral reflex and reaction of the bowel to Metamysyl (methyldiazyde $[28,29]$.

In normal circumstances the brutal increasing of pressure $(170 \mathrm{~mm}$ $\mathrm{Hg}$ ) in a latex balloon introduced into the animal rectum, provokes a motility stop in the small bowel within less than $10 \mathrm{sec}$ (Figure $2 \mathrm{~A}$ ). If the stop occurs later than after $20 \mathrm{sec}$, it may due to humoral (adrenalin) intervention, as far as the recirculation time for dogs is about $20 \mathrm{sec}$. After interruption of the central innervation of the NRI or transplanted small bowel none reflex stop of the graft motility cannot be waited. The eventual reappearance of this reflex may be a sign of nervous reflex restoration.

The intra-muscular injection of Metamysyl /methyldiaside/, a cholinolytic ( anticholinergic) substance at the rate of $0.5 \%$ solution $-150-200 \mathrm{mcg} / \mathrm{kg} \mathrm{BW}$ ) causes a motility inhibition within about 3-4 min 
Citation: Coulic V, Mikhalsky DV, DePrez C, Delree P, lesuitova NN, et al. (2015) About the Respective Roles of Central and Intraorgan Nervous Systems in Regulation of the Gastrointestinal Tract Physiology and Morphology. Brain Disord Ther 4:172. doi:10.4172/2168-975X.1000172
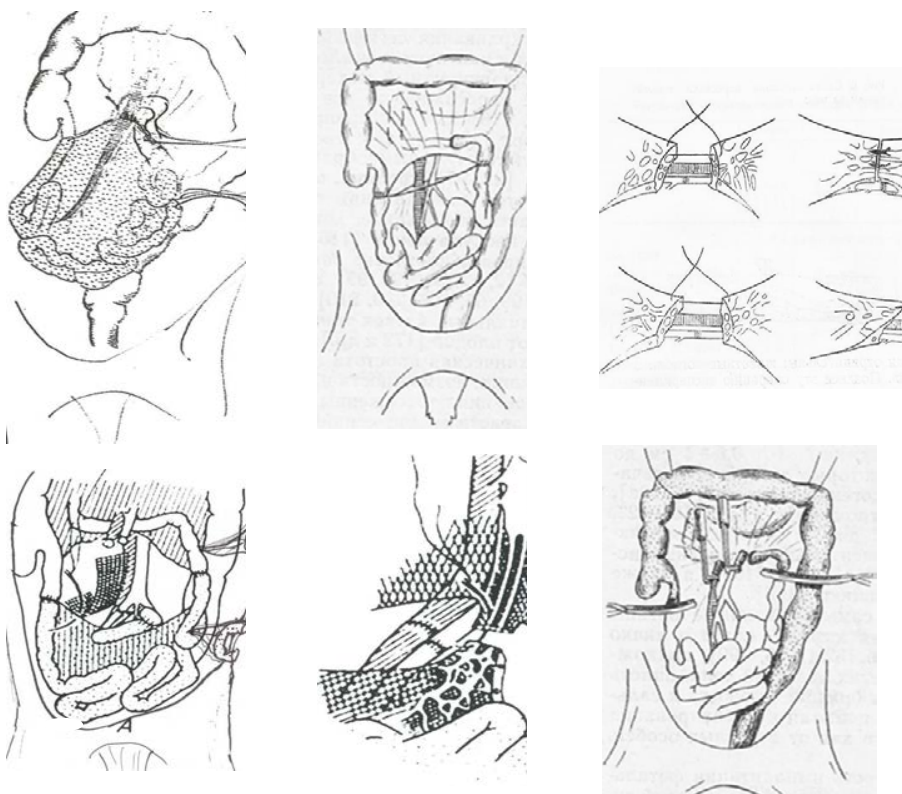

Figure 1A: Schemas of surgery models in dogs: a) Orthotopic utotransplantation of jejunum and ileum. The dotted surface represents the graft. Arrow : isolated byThiry-Vella method loops isolated from intact and grafted parts of the small bowel. b) Heterotopic autotransplantation of the small bowel (jejunum and ileum) with vascular connections of the graft to external iliac artery and vein. Isolation of intestinal loops by Thirry-Vella method from both intact and transplanted bowel. c) Interruption of nervous connections between jejunum-ileum and central nervous system by dividing mesenterium and small bowel continuity (NRI). d) Para- and epineural stiches for suture of divided mesenteric nervous plexus (SDR : surgically directed re innervation). e) Surgically directed re innervation in heterotopic conditions with the use of a flap containing a part of the presacral plexus for suture with the mesenteric plexus of the graft. $\mathrm{f}$ ) Temporary ischemia of the jejunumileum: the mesenteric vessels and small bowel are clamped for $50 \mathrm{~min}$. Clamps on proximal part of the mesenteric vessels and on the proximal and distal segments of the small bowel.
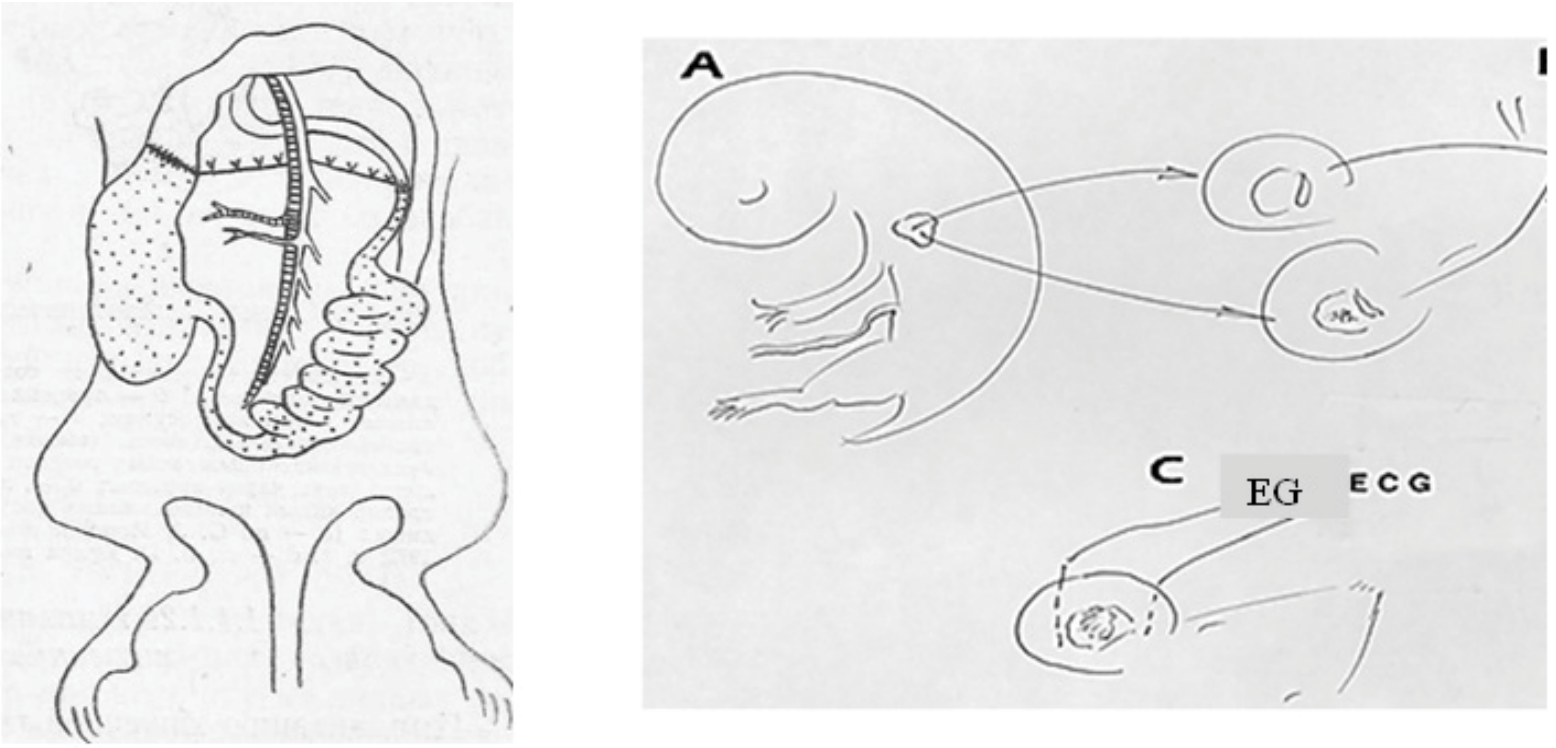

Figure 1B: Schemas of surgery models in rats: $\mathrm{g}$ ) Orthotopic autotransplantation of the small bowel with the caecum and a part of colon ascendens (the dotted area represents the graft). h) Implantation of a fœtal intestine (left) into a subcutaneous pouch of the adult rat ear (right). Possibility of electrode insertion for the graft electric activity registration. 

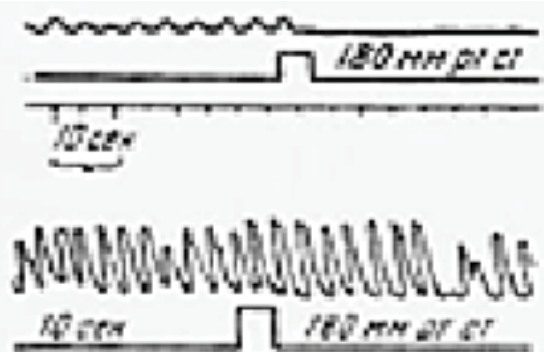

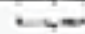

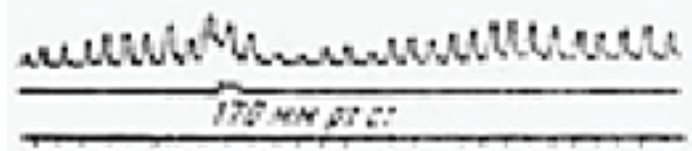

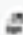

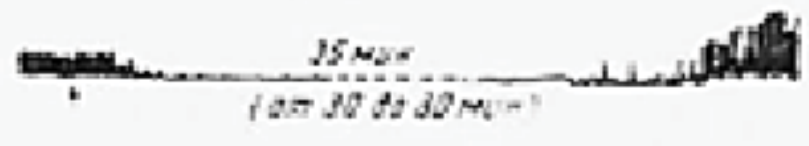

6
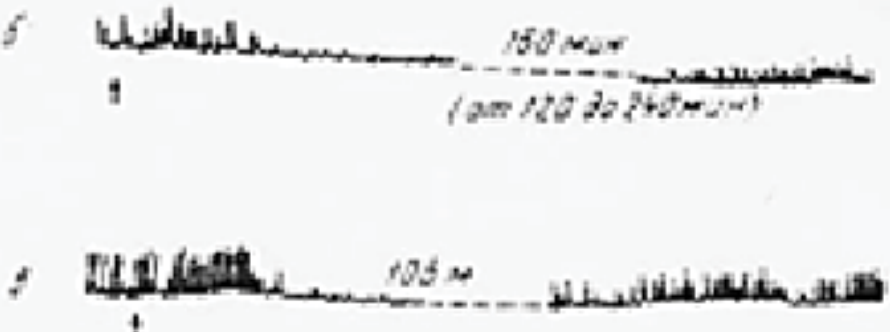

Figure 2A and 2B: (A) Methods for testing the neuroreflex isolation of the small bowel. Registration of the recto-enteral reflex (RER). On each graphic: above registered bowel contractions (by manometry / balloon kymography method) of a Thirry-Vella loop; lower: registration of the pressure created within the intra rectal baloon (170-180 MM Hg during $10 \mathrm{sec}$ ); beneath : time registration in 10 second intervals. a) Normal inhibitory reaction in sham operated dog by the same method of motility registration (starting within $10 \mathrm{sec}$ after stimulation (conventional estimation $=5$ ) ; b) absence of any reaction after NRI or transplantation of the bowe (conventional estimation $=0$ ) ; c) beginning of a partial inhibitory reaction 6 months after NRI or transplantation of the bowel. (B) Registration of inhibitory effect of intramuscular injection of 0,5\% Metamysyl (150-200 mcg/kg BW) on the small bowel motility. a) Normal inhibitory reaction 25 min duration in sham operated dog, b) excessive inhibitory reaction during $150 \mathrm{~min}$ after NRI or transplantation of the small bowel; c) beginning slow reduction of the inhibitory reaction duration (103 min) 8-9 months after NRI or transplantation of the small bowel .

and this stop prolongs up to $30-40$ min (Figure $2 \mathrm{~B}$ ). According to the law of Cannon-Rosenbluth about increased sensitivity of denervated structures to humoral agents, an increasing of the stop reaction in intensity and duration has to be waited [30]. Normalization of the intestinal response to this neurotropic agent may also be a sign of innervations restoration.

Motility activity was registered by manometer (balloon kimographe) method which allows measuring both tonic and segmental contraction activities [31-33]. Transit of contrasted (Barium sulfate) standard meal was also registered by radiologic observation (standard device used in the USSR human clinics)

Secretion activity was determined by intestinal juice collection from Thirry-Vella loop during 3 hours, centrifugation at 1000 turns/ min during $10 \mathrm{~min}$, measure of supernatant and solid part volume and determination in both parts of alkaline phosphatase and enterokinase. These enzymes are secreted by the small bowel. Though actually they are no more taken in consideration thanks to novel data about them, in our experiments their variations under different situations still may be considered as liable signs of secretion alterations. The biochemical method of their determination is based on the $\mathrm{pH}$ modifications under the influence of alkaline phosphatase during the "digestion" of a standard solution, and the disappearance of colloid aspect of a standard protein probe in presence of "enterokinase") [34-39]. Measures were provided in 12 hours fasted animals and after standard meal feeding ad libido.

General condition, BW evolution, faeces alterations were also considered: their evaluation was performed once a day during the first 2 weeks, then each 14 days and after 2 months once a month.

Morphology investigations were provided after necropsy of the animals (euthanatized by Thiopental overdoses): organ samples were collected, fixed in formaldehyde or glutaraldehyd $10 \%$, embedded in paraffin or epon, and the slices 4-6 $\mu$ were stained by haematoxylin eosin, Schiff reactive, van Gieson method, the acid phosphatase and succinate dehydrogenase of intramural neurons were tested by Nachlas and Gomori methods and nervous fibers growth - with Argentum impregnation by Compas or Gross-Bielschovsky methods [17].

In rats: with NRI - membrane digestion was investigated by the method of inverted intestinal loop [40-42].

In rats with fetal organ implants, physiological methods used to test the graft function were:

Registration of electric activity of growing fetal stomach graft from needle electrodes implanted in the ear pavilion on both sides of the growing implant by a physiograph (Pathfinder II, Nicolet Biotechnics), Ultra sound - echography screening of the ear (IU 22 Philips - NL device with a L17-5 probe) $\mathrm{pH}$ metry of the intestinal and gastric contents (by strips), before and after feeding the gastric implants with $5 \%$ glucose or ABS solutions injected into their lumen.

Host blood and urine biochemistry (strips "Accutrend") was provided in the case of induced (by intra peritoneal injection of Streptozotocin solution - $0.75 \mathrm{mg} / 100 \mathrm{~g}$ BW) Diabetes Mellitus for testing the functional activity of the grafts.

Morphological methods: in vivo trans illumination biometry of the graft using the light of an endoscope, and after biopsy or necropsy of animals under anesthesia or after euthanazia (by anaesthetics overdose), samples were fixed in $12 \%$ formalin, paraffin embedded, 4-6 $\mu$ slices were stained by hematoxilin eosin saffron. Immunohistochemistry methods and electron microscopy were also used for detection of pancreatic hormones - insulin, glucagon and somatostatin.

Statistics: no less than 5 probes were considered for testing results by variation statistics methods with standard deviation (+/- SD) and liability (p) determination using the Student criterion. 


\section{Results}

\section{BW, general condition and coprology}

After NRI, BW loss was about $20 \%$ within 2 first post operations week followed by a slow increasing and stabilization within 6 months at a level a little inferior relatively to the time 0 one. The coprology investigations have shown significant alterations: liquid consistence, fetid odor, diarrhoea (at least 8-10 stools/day during at least 2 months), creatorhoea, amylorhoea, steatorrhoea, presence of mucus filaments, muscular fibers and practically intact elements of food. Later diarrhea decreased: during 24 hours observation 4-6 liquid stools and solid fecal masses were registered. But coprophagy had started: stools showing weak signs of digestion were reabsorbed and have repeated the gastrointestinal transit. This situation was maintained till the end of the observation.

The same situation was observed after ortho- or heterotopic Tx of the small bowel, not after ischemia or Thirry-Vella loop installation.

When SDR was performed, the same observations were made but only during 4 weeks after NRI+SDR and 2-4 months after Tx+SDR. BW increased through 4 months for NRI+SDR, 6 months for Tx + SDR and reached the incoming level. The same observations were made about general condition and coprology. After 6-8 months for NRI+SDR, 12 months for orthtopic Tx + SDR and 18 months for heterotopic Tx + SDR, the dogs appeared to have completely recovered initial general condition and behavior.

\section{Connections between CNS and small bowel}

In control series, after operative trauma (laparotomy and isolation of small bowel loops by Thirry-Vella method), as well as after small bowel 40-50 min ischemia, RER remained present (total motility inhibition within 5-6 sec after pressure increase to $170 \mathrm{~mm} \mathrm{Hg}$ in the rectum balloon during $10 \mathrm{sec}$ ). Motility inhibitory reaction to Metamysyl injection was not altered and its duration varied between $60.0+/-13.7$ and $82.0+/-10 \mathrm{~min}$.

After NRI from day 2-3 ( $1^{\text {st }}$ investigation) to month 5 no reaction arose in answer to quick increase of intra rectal pressure and no complete recovery up to the end of observation. The same observation was made in the series with Tx. After SDR during 1-2 days some answer was detected, after what the small bowel did not react to rectal stimulation during 1-2 months. Within the $3 \mathrm{~d}-4^{\text {th }}$ month the reaction normalized in all the NRI dogs. After Tx + SDR the time for complete restoration of RER was 6-8 months for orthotopic Tx and up to 18 months for heterotopic Tx (Figure 2C).

As for Metamysyl inhibitory influence on the small bowel motility, its duration was significantly increased after NRI and Tx and never returned to normal values. In case of SDR the increased answer to the substance was always observed but a progressive normalization was noted beginning from month 4 in NRI + SDR, from month 8-10 in Tx. Complete restoration was observed some later (Figure 2D).

\section{Motility}

Investigation after NRI has shown periodic contractile waves characterized by significant decreasing of segmental contractions and dramatic increasing of the tonicity (up to $90 \%$ of the motor complex surface) (Figure 3A). After several weeks, the proportion of T/P diminished but remains higher than in control experiments. After Tx the same alterations were observed and maintained all through the experimental observation. After SDR, normalization begins after 4 weeks and was complete within 6-18 months. In controls (temporary ischemia and Thirry-Vella loops installation), alterations observed did not prolong more than 14 days, but they were different: in Thirry-Vella loops - they consisted in a slight temporary increasing of the tonicity component (up to $40 \%$ of the surface); in the ischemia cases, on the contrary, both components were significantly diminished during 5-7 days, the complete recovery being observed after 2 weeks.

Transit investigations have shown a drastic decrease of the duration of nutriment bolus passage through the NRI or Tx small bowel (less than one hour instead of 2-3 Figure 3B). The beginning of gastric emptying was not modified but the moment of complete emptying was drastically increased (reaching 7-8 hours instead of 1-2 hours). In contrast, the complete transit including through colon was decreased: about 10 hours instead of 20. It was explained by the quick instauration of a new evacuation pattern: gastric emptying was fractioned, each following portion being pushed into duodenum and jejunum only after complete emptying of the NRI small bowel into the caecum (Figure 3B a-c) So the first stools appeared within 30-60 min and were semi liquid, slightly different of the ingested food, then... eaten by the animal for a second digestion cycle. In NRI and TX the situation remained unchanged till the end of observation. If SDR was performed, slowing of the transit through the small bowel began through 2-6 months and the transit normalization with coprophagy disappearance was obtained after 6-18 months (depending on the kind of operation). Such features were never observed in both control series -operative trauma by Thirry-Vella loop installation, and temporary ischemia of the small bowel.

Secretion function after NRI was also significantly perturbed, particularly when provoked by mechanic stimulation secretion. The alterations concerned the whole quantity of collected juice, mainly depending on the significantly increased liquid part, the solid part being also increased but less, so its percentage, relatively to the whole juice quantity, was diminished. This "paralytic" hyper secretion has started during the first days after NRI and prolonged till the end of observation period (Figure 4). In Tx series, the observed secretory alterations were the same in quality, quantity and duration. In the case of SDR, their manifestation diminished after 4 weeks and normalization occurred between 2 and 6 months, depending on the series (NRI or Tx). The enzyme contents $/ \mathrm{ml}$ of solid part was not significantly modified in comparison with the control data.

Membrane digestion after NRI showed no significant difference between controls (intact rats, laparotomy with 50-min exposition of the bowel) and NRI could be determined at any delays.

Morphology after Tx, NRI, ischemia, SDR growth of neurons The same alterations were found in Tx series but not in NRI without or with SDR [17]. After NRI sub epithelial oedema and increased desquamation of the villi, some decrease of enzyme expression in the neurons, were noted during the first days, but no apoptosis or necrosis. Later a tendency to inflammation and erosions was observed as well as outlying position of the nuclei in some neurons of the myenteric plexus.

After Tx series during the first 15 days basal oedema of the enterocytes with displacement of the nucleus in apical direction was noted. Slights alterations of the neurons of the myenteric plexus were also observed: apoptosis signs, outlying nuclei. Later the condition of the grafted intestine seemed to improve and only the same alterations as in NRI series were detected. Control series with $<60 \mathrm{~min}$ warm ischemia has shown reversible basal oedema of enterocytes and increased desquamation of the villi, as well as serious alterations of the intramural 
Citation: Coulic V, Mikhalsky DV, DePrez C, Delree P, lesuitova NN, et al. (2015) About the Respective Roles of Central and Intraorgan Nervous Systems in Regulation of the Gastrointestinal Tract Physiology and Morphology. Brain Disord Ther 4:172. doi:10.4172/2168-975X.1000172

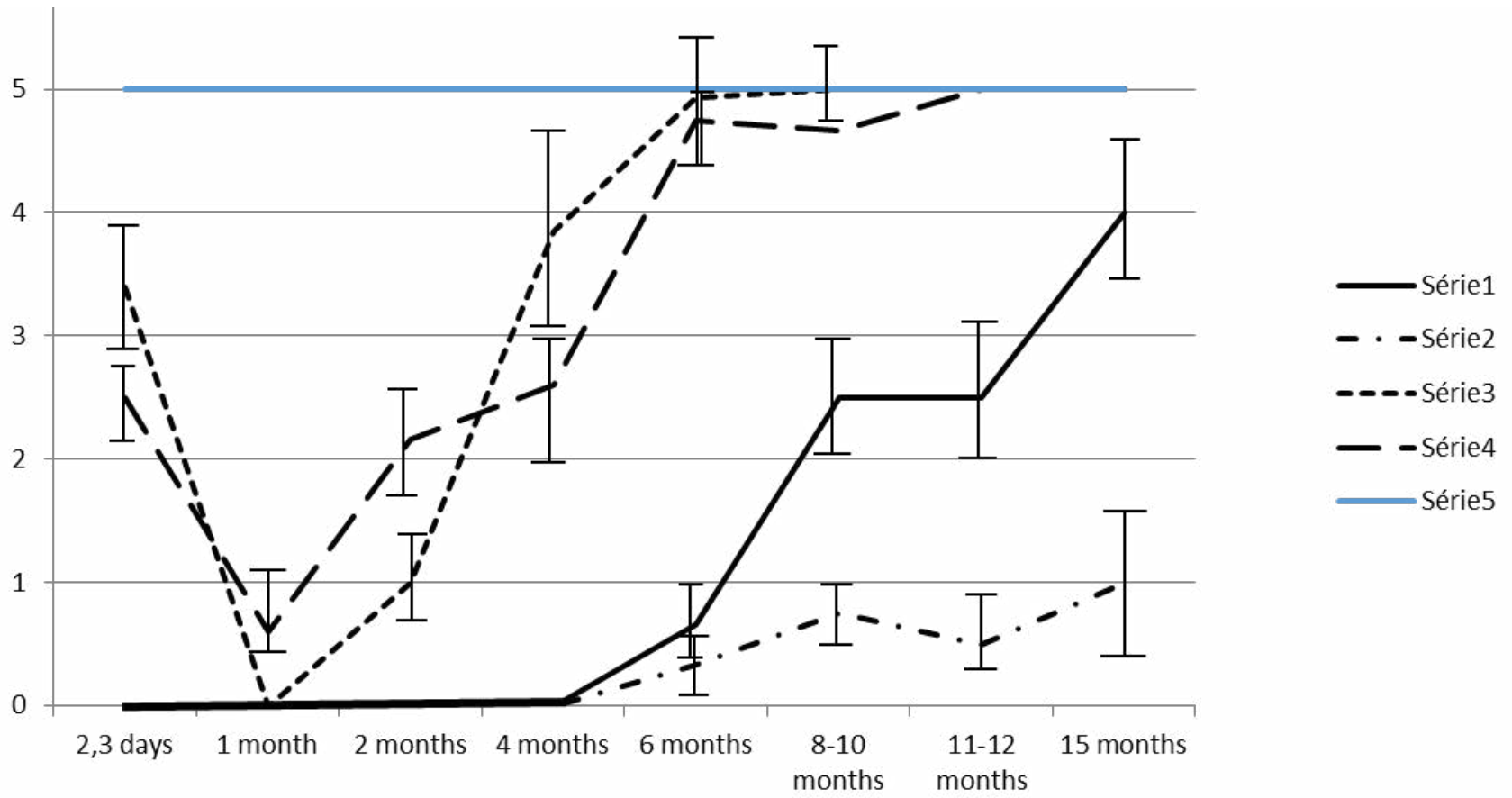

C) Rectoenteral reflex

Figure 2C: Results of RER investigation depending of the operation model and the post operation delay (M+/-SD). In abscissa - time in months; in ordinate conventional estimation of the reaction: 0 - no reaction, 5 - total inhibitory reaction starting within 10 sec after stimulation. Plain line - NRI; punt-hyphen_... line: heterotopic transplantation $(\mathrm{HTx})$; ---- line : neuro reflex isolation with surgically directed re innervation (NRI+SDR) ; line : heterotopic transplantation with surgically directed re innervation (HTx+SDR). In the operations with SDR, normalization of the RER began after 2 months and was complete within 6 months after $\mathrm{NRI}+$ SDR and 8 months after HTx+SDR. The RER recovery was only partial in the case of NRI and especially after HTx ( $p<0.01)$

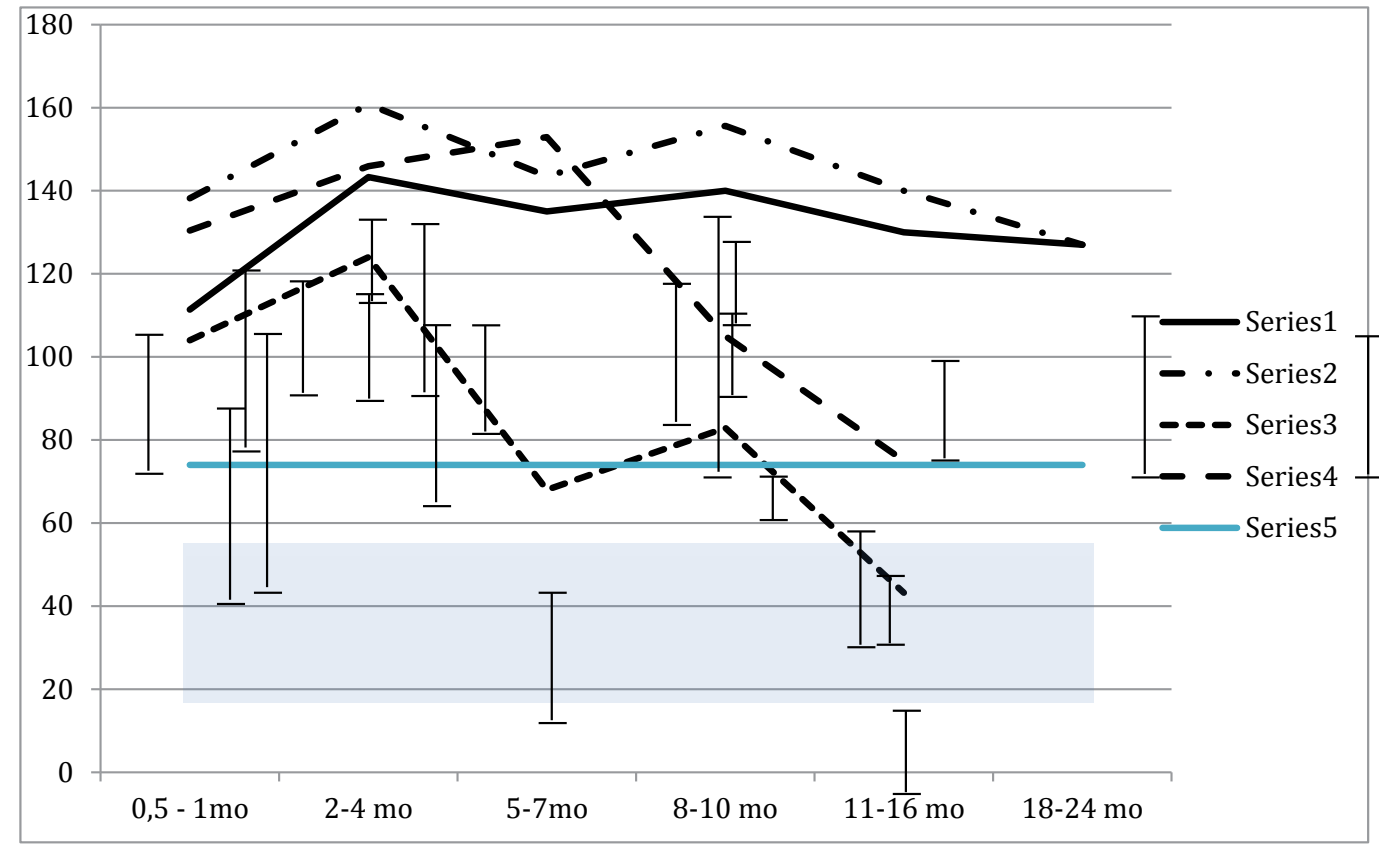

D) Reaction to metamysyl

Figure 2D: Results of the Metamysyl test (M+/-SD). Abscissa - time in months; ordinate: duration of the small bowel motility inhibition in min. Series - the same as in $\mathrm{C}$. In the case of surgically directed re innervation (SDR) the reaction differed no more from the normal mean respectively through 5-7 months after NRI and only through 11-16 months after HTx. No normalization was to be noted after NRI or HTx. 
Citation: Coulic V, Mikhalsky DV, DePrez C, Delree P, lesuitova NN, et al. (2015) About the Respective Roles of Central and Intraorgan Nervous Systems in Regulation of the Gastrointestinal Tract Physiology and Morphology. Brain Disord Ther 4:172. doi:10.4172/2168-975X.1000172

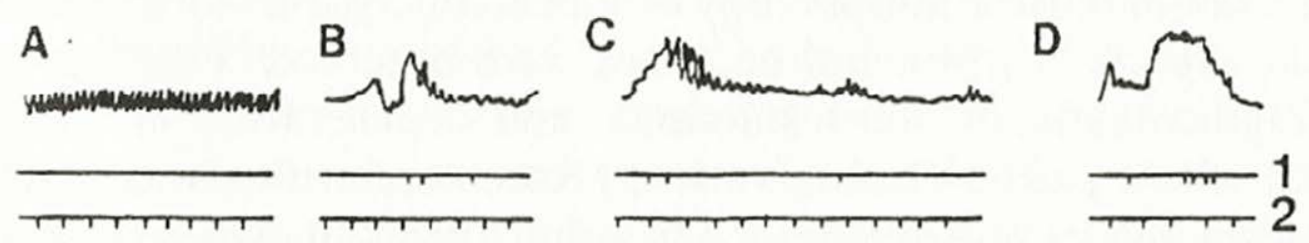

E
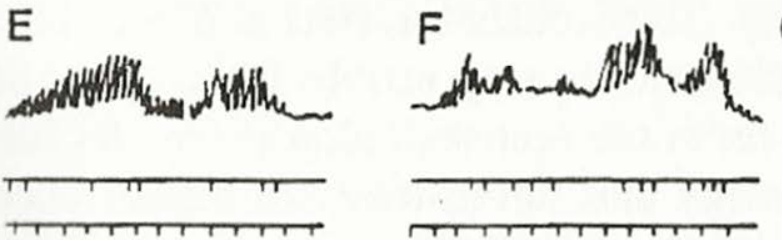

G

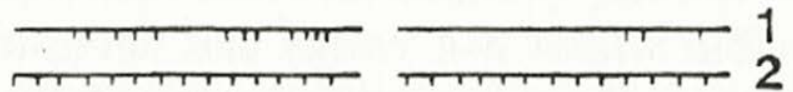

Figure 3A: Evolution of the motility function. A) Peculiarities of the small bowel motility at different moments after auto transplantation (Tx) or neuroreflex isolation (NRI). Above : manometry (balloon kymography) registration of the bowel activity, lower (1) : registration of the movement of the balloon within intestinal lumen - 1 mark $=1 \mathrm{~cm}$; beneath $(2)$ : time registration in 1 min intervals $. a-$ During anaesthesia ; $b-c:$ during the first post operation day ; $:$ day $5 ; \mathrm{e}:$ day $7 ; f:$ day 14 ; $\mathrm{g}$ : day 30 after auto transplantation. Note the high level of tonicity, which correspond to quick translation of the intra luminal balloon.

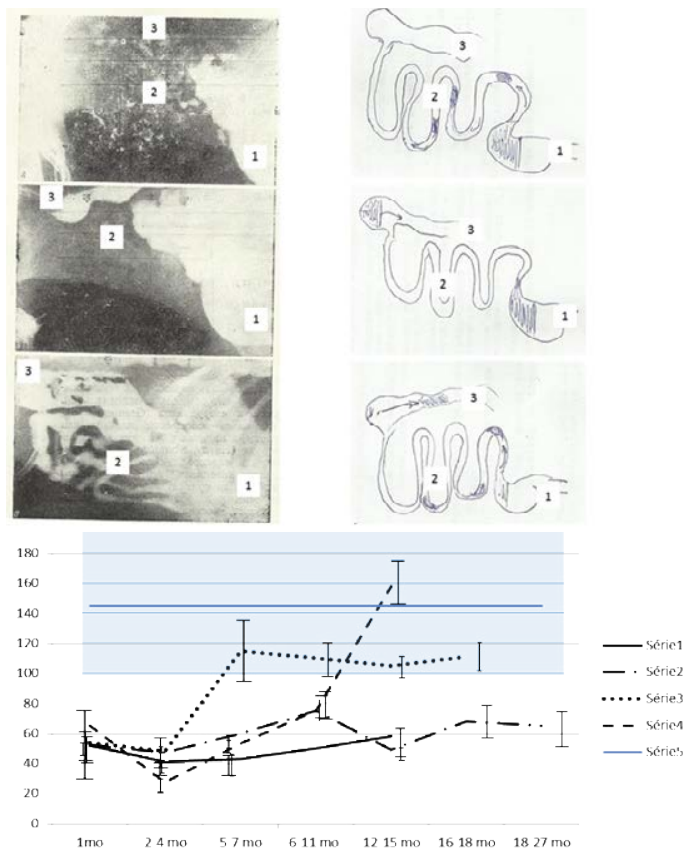

Figure 3B: Evolution of the motility function. A) Peculiarities of the small bowel motility at different moments after auto transplantation (Tx) or neuroreflex isolation (NRI). Above : manometry (balloon kymography) registration of the bowel activity, lower (1) : registration of the movement of the balloon within intestinal lumen - 1

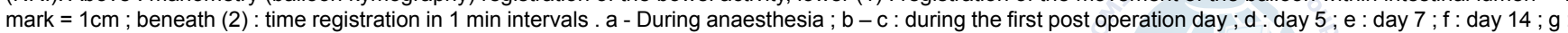
day 30 after auto transplantation. Note the high level of tonicity, which correspond to quick translation of the intra luminal balloon B) Peculiarities of a contrasted food bolus transit through gastrointestinal tract after small bowel auto transplantation (or NRI)1.Rentgenoscopy images and schema at different moments after ingestion of standard meal with barium sulphate: a. through $20 \mathrm{~min}$ :stomach full, beginning of the transit into the graft ; b. through 40 min - stomach full, grafted intestine empty, caecum with the first portion of the bolus ; c. through 2 hours : stomach almost empty, a bolus into the NRI small bowel, caecum and colon half full (because some previous boluses have already been evacuated). 1. Stomach; 2 . Grafted intestine; 3. Caecum and colon ascendens. 2.Graphics of the evolution of the food bolus transit after different operations : a significant acceleration is noted in all the series during the first 4 months after operation, then a graduated normalization may be observed in the series with SDR, while the significant difference with control $(p<0.01)$ is maintained till the end of observation in the NRI and HTx series. In blue - control (sham operation: isolation of Thirry-Vella loop), Plain line - NRI, ... line Heterotopic transplantation (HTx) ; ---- line : neuroreflex isolation with surgically directed re innervation (NRI+SDR) ; _ _ line : heterotopic transplantation with surgically directed re innervation (HTx+SDR). 
Citation: Coulic V, Mikhalsky DV, DePrez C, Delree P, lesuitova NN, et al. (2015) About the Respective Roles of Central and Intraorgan Nervous Systems in Regulation of the Gastrointestinal Tract Physiology and Morphology. Brain Disord Ther 4:172. doi:10.4172/2168-975X.1000172

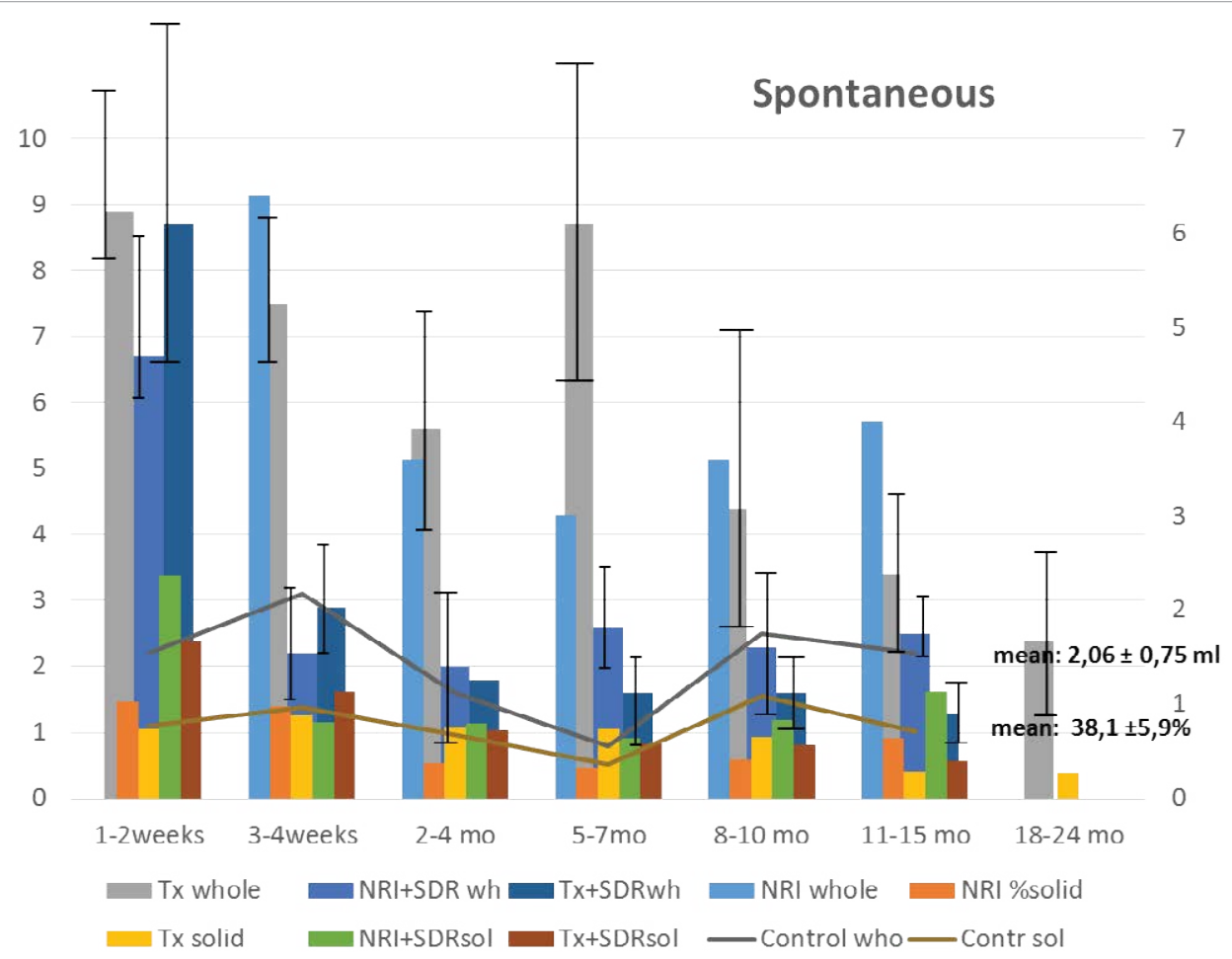

A.Spontaneous secretion

Figure 4A: Evolution of the secretion activity. Spontaneous secretion - whole volume collected during 3 hours (ml), and volume of the solid part relatively to the whole secretion volume $(\%)$ (obtained after $10 \mathrm{~min}$ centrifugation at $2000 \mathrm{~g} / \mathrm{min}$.A significant increase of the whole secretion volume of the intestinal juice with a constan solid part that means a relative decrease of this solid part in all the experimental series during the first month after the operations. In series with surgically directed re innervation (SDR) a tendency to normalization has been observed since the second post operation month and normalization may be considered as complete at months $2-4$. For the series without SDR this process has been much longer, never being quite complete $(p<0.5)$.

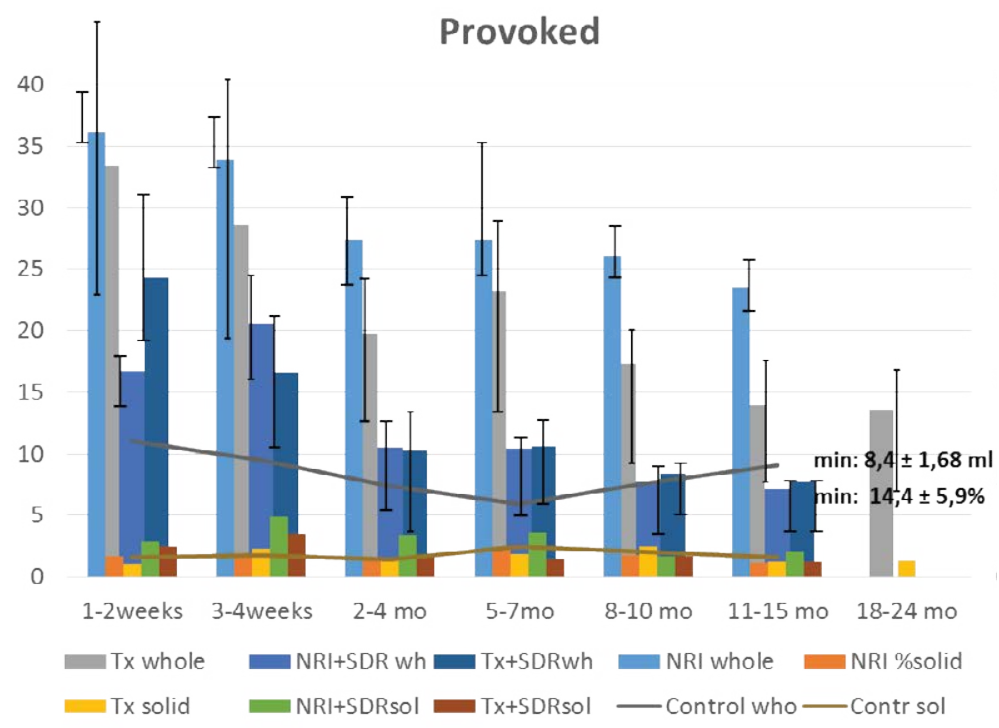

B.Provoked secretion

Figure 4B: Provoked (by the presence of a catheter within the intestinal loop) secretion: - whole volume collected during 3 hours; and volume of the solid part relatively to the whole volume (\%).Hypersecretion of the intestinal juice mainly of its liquid part is well expressed in all the experimental series. In the series with SDR a tendency to normalization is noted after 2-4 months and achieved at months 8-10. In series NRI and Tx no improvement of the hypersecretion can be detected all through the observation period. 


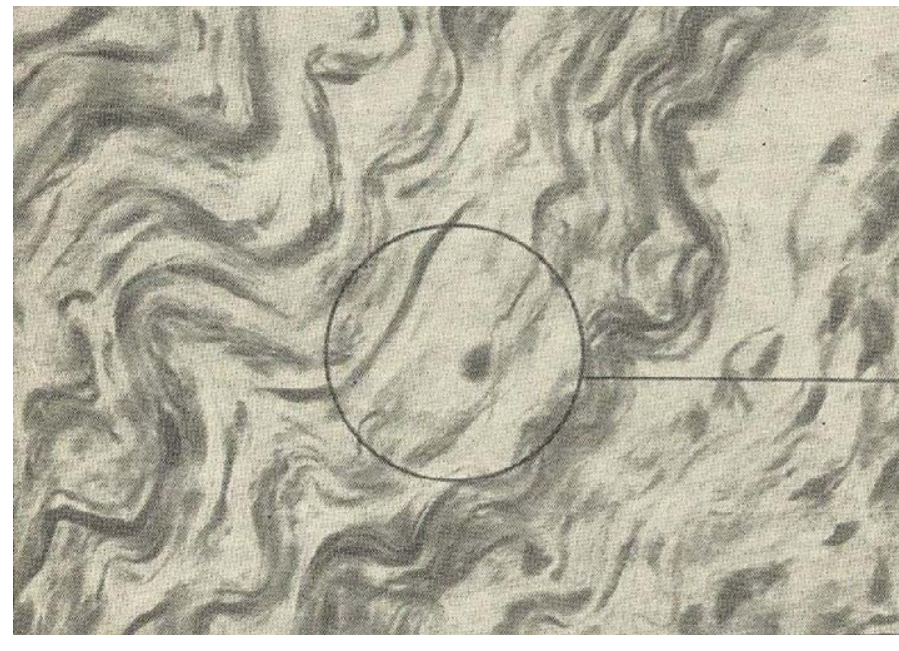

Morphological proof of reinnervation.

Figure 5: Histology of the operated bowel mesenterium 5 days after neuroreflex isolation (NRI) and surgically directed re innervation (SDR). A growth bud is observed ( $\mathrm{G} \times 100$, staining by Gross Bielschowski).

neurons. These alterations lasted only a fortnight (14 days). So, the observed alterations of the intestinal transplant morphology looked a sum of the disorders caused by ischemia and NRI. After SDR signs of the neuron axons growth were found in the zone of nervous sutures, as well as in nerves of the grafted small bowel mesentery (Figure 5).

\section{Function and morphology of fetal stomach and intestine grafts}

After implantation of fetal small bowel or stomach into an ear pavilion subcutaneous pouch a general destruction of the implant with disappearance of tissue structure and of most typical cells: a kind of primitive "porridge" rich in weakly differentiated cells was observed (Figure 6 a). At the end of the first week formation of lacunas and blood capillaries and of cavities lined by cubic epithelium cells could be noted (Figure $6 \mathrm{~b}$ ). Further a reconstitution of normal intestinal or gastric wall developed following typical ontogenetic pattern: differentiation of the different layers and cells in them (Figure $6 c$ and $6 \mathrm{~d}$ ). Very early, as intestinal muscle layers began to form, neurons appeared between them. They were displayed in numerous ganglia. Interesting that in "wild" intestine implanted into a GPF marked mouse, part of neurons were GPF positive (Figure 6e). This testifies in favour of their recipient origin. Fetal gastric implants developed in the same way and presented gastrin marked cell in their epithelium (Figure 6f). Grown from fetal implants adult-like organs were functional. In fetal intestinal implantation, after milk injection into the lumen of re-formed intestine, electron microscopy of the villi has shown absorption of chylomicrons through a perfectly normal epithelial structure (Figure 6e). Electric periodic activity was registered in gastric implants, as well as variation of the $\mathrm{pH}$ of their juice after "feeding" (Figure 7).

No evidence of penetration of the implants by host nerves and no data about a correlation between the host digestive activity and the graft function were found up to now. In pancreatic fetal implants the organ was not completely restored: only isolated endocrine cells, sometimes clusters, may be some exocrine tubes, were found without genuine reconstruction of an adult-like pancreas (Figure 8a and 8c).
Nevertheless in certain conditions, fetal pancreatic grafts were able of an endocrine insulin activity: if a sufficient quantity of them was implanted, improving and even "healing of Streptozotocin induced Diabetes mellitus could be obtained (Figure 8d). The same observation is true for liver fetal implants: well developed hepatocytes columns and normal bile ducts were found but without connection between them or signs of bile formation (Figure 9).

\section{Discussion}

Dog experiments have then shown that NRI, i.e. the chronic nervous reflex connection interruption of the small bowel with CNS significantly affects neither the intestinal morphology (except oedema and increased desquamation of the villi, some decrease of enzyme expression in the neurons, during the first days, but no necrosis), nor its intrinsic functional capacity. This means that motility, secretion and membrane digestion capacity are qualitatively intact. But the ability to quick (within less than $10 \mathrm{sec}$ ) reflector reactions as RER, relations between motility tonic and peristaltic components, answer to nervous transmitters and other substances circulating by vascular way, food transit, quantities and dilution of secreted substances and resulting nutriment, assimilation - are significantly impaired, that explains a degradation of the animals general condition. The impression is that the NRI small bowel function has become mostly independent of the whole body organization. The same kind of disorders, particularly hypermotricity of the graft were also observed after small bowel transplantation in experiments, as well as in clinics [43,44].

At the same time 24-hour observation in our experiments has allowed detecting several important modifications in the function of organs remaining in connection with the CNS: drop emptying of the stomach in coordination with registration by caecum of the previously sent bolus arrival. A significant behavioural modification of the animal is instated: appearance of coprophagy of the partially digested faeces. All these registered peculiarities have an adaptation character and lead to a stabilization of the animal welfare: stop of the diarrhoea, body weight stabilization (but at a level inferior to the initial one) and exterior appearance improvement. They also masked the real alterations 
Citation: Coulic V, Mikhalsky DV, DePrez C, Delree P, lesuitova NN, et al. (2015) About the Respective Roles of Central and Intraorgan Nervous Systems in Regulation of the Gastrointestinal Tract Physiology and Morphology. Brain Disord Ther 4:172. doi:10.4172/2168-975X.1000172
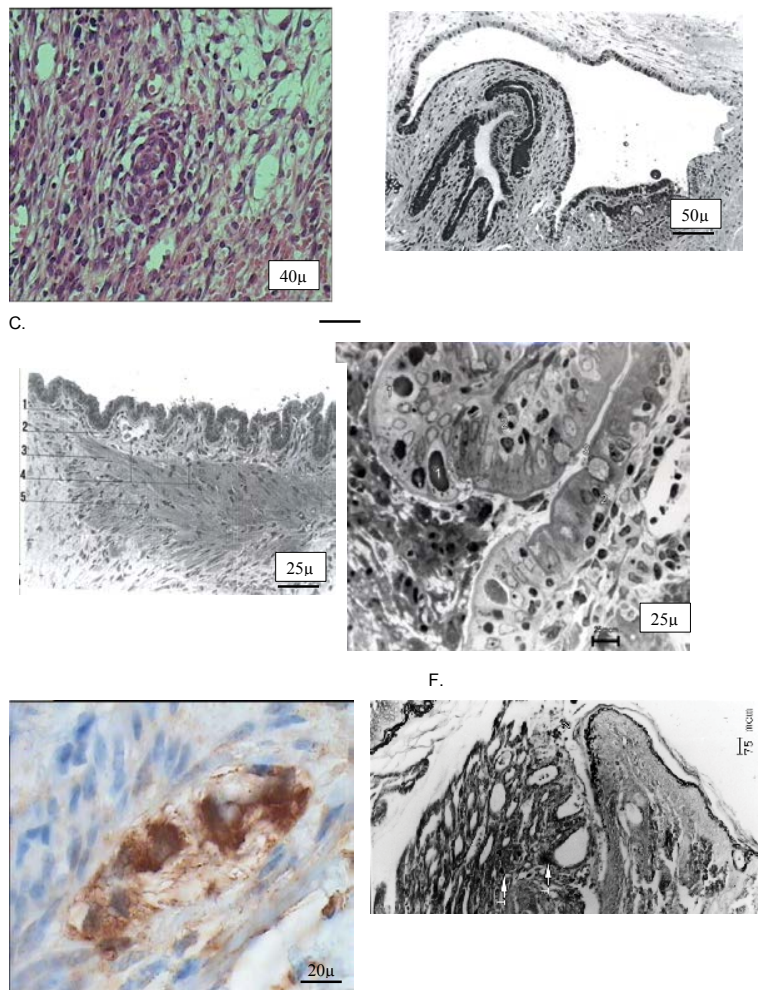

Morphology of fœtal organ implant

Figure 6: Morphology of fœtal digestive organ evolution after implantation.A.Transillumination view of a growing fetal small bowel (arrows) at day 30 after implantation into a subcutaneous pouch of the rat ear. B. Histology of the implant: a . Day $4:$ destructuration of an intestinal implant with necrotic remnants of villi, inflammatory cells and many weakly differentiated cells (Hematoxilin eosin, x 20); b. Day 7 : Formation of a cavity lined by cubic epithelium (Hematoxylin eosin, $x 20$ ) ; c. Day 28 : Re-development of the different small bowel layers - 1-mucosa with enterocytes and calicial cells, 2 - muscular layers (hematoxylin eosin, $x 20$ ); $d$; Day 60 : Electron microscopy of a grown intestinal villus with normal structure and microchylons penetrating the enterocyte layer (1); e. GPF marked neurons of Auerbach plexus in a grown fetal intestine implant 4 months after the operation (the donor was a « wild » C53BI mouse, the recipient a GFP positive animal); (G x 100), f. Fetal stomach 4 months after implantation at the ear site. Arrow : junction of the mucosa layer with the skin of the host and somatostatine positive cells.

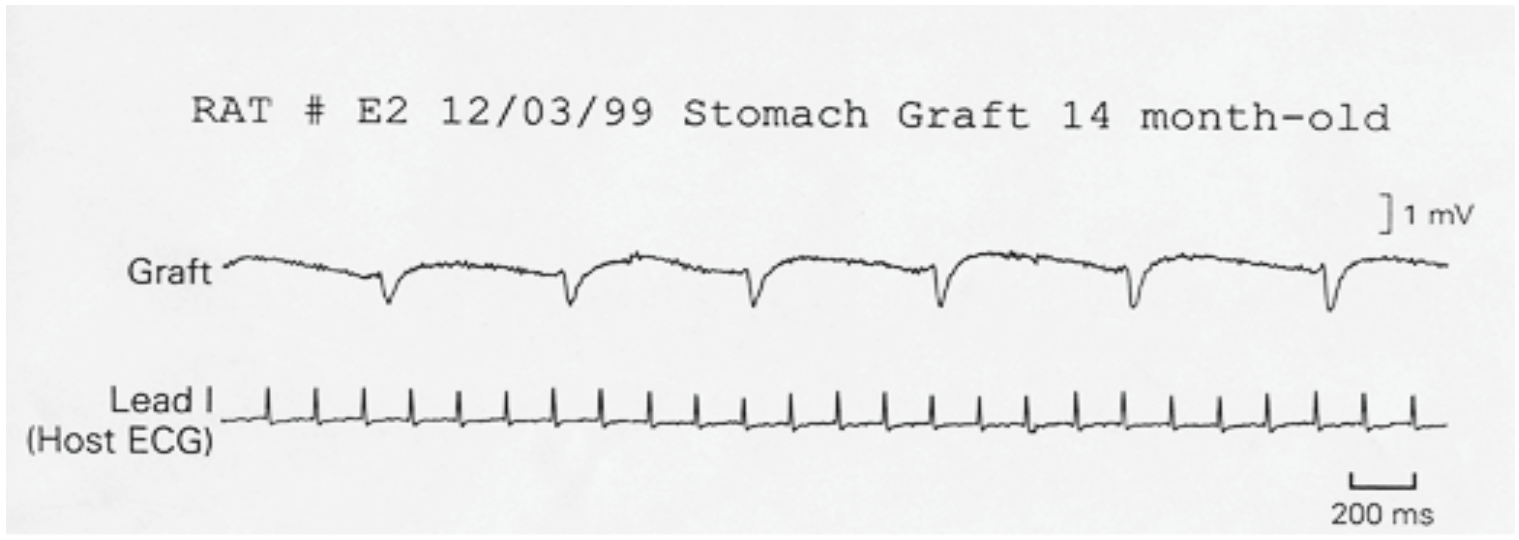

A. Electric activity of a fetal stomach implant.

Figure 7A: Function of the grown fetal gastric implant at month 14 after operation. Electric activity (motility) of the implant. 
Citation: Coulic V, Mikhalsky DV, DePrez C, Delree P, lesuitova NN, et al. (2015) About the Respective Roles of Central and Intraorgan Nervous Systems in Regulation of the Gastrointestinal Tract Physiology and Morphology. Brain Disord Ther 4:172. doi:10.4172/2168-975X.1000172

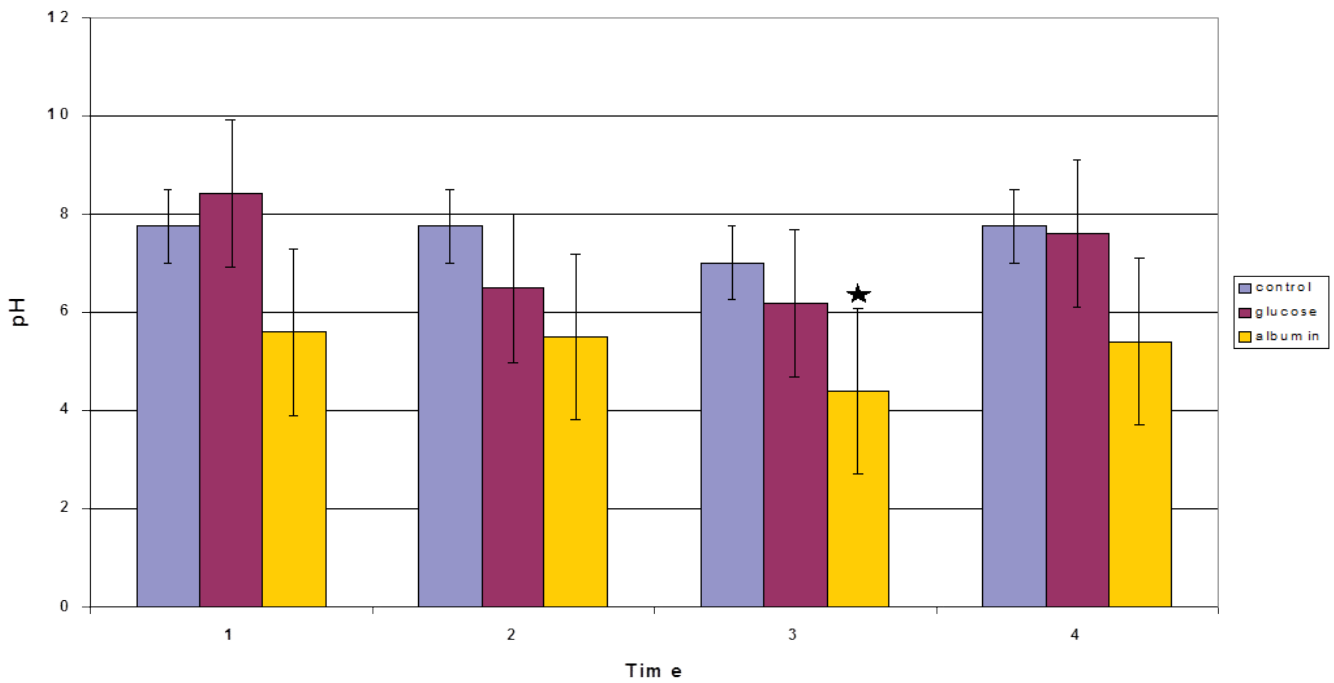

Figure 7B:Secretory activity of the implant: acidification of the lumen contents after " feeding » with Bovine Albumine (columns on the right) and nonsignificant tendency after saline injection into the implant lumen (central column). Note that without stimulation the $\mathrm{pH}$ of the stomach implant secretion is neutral and after stopping the stimulation it returns to neutral. In abscissa - observation days, in ordinate - $\mathrm{pH}$ values from 3 to 8 .

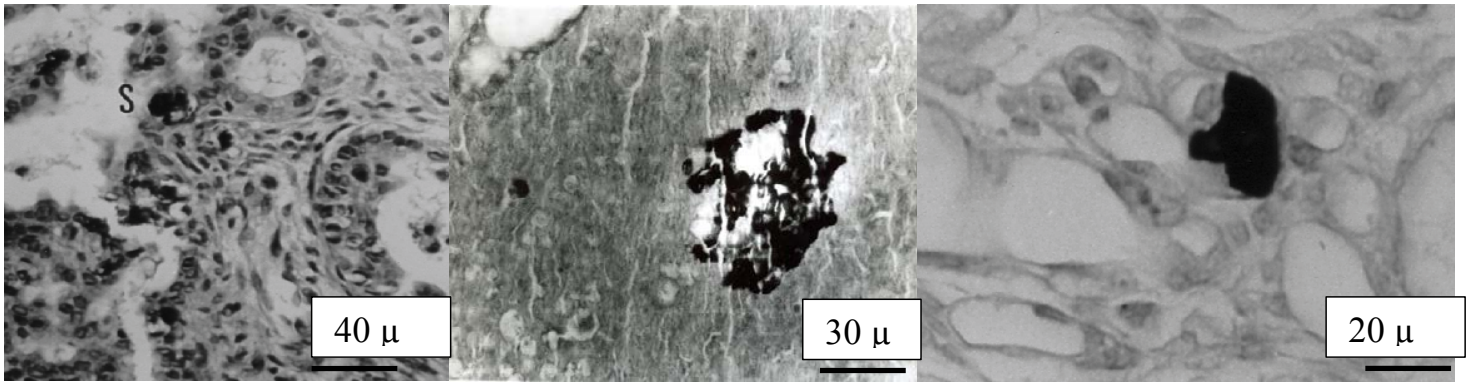

Somatostatin

Glucagon

Insulin

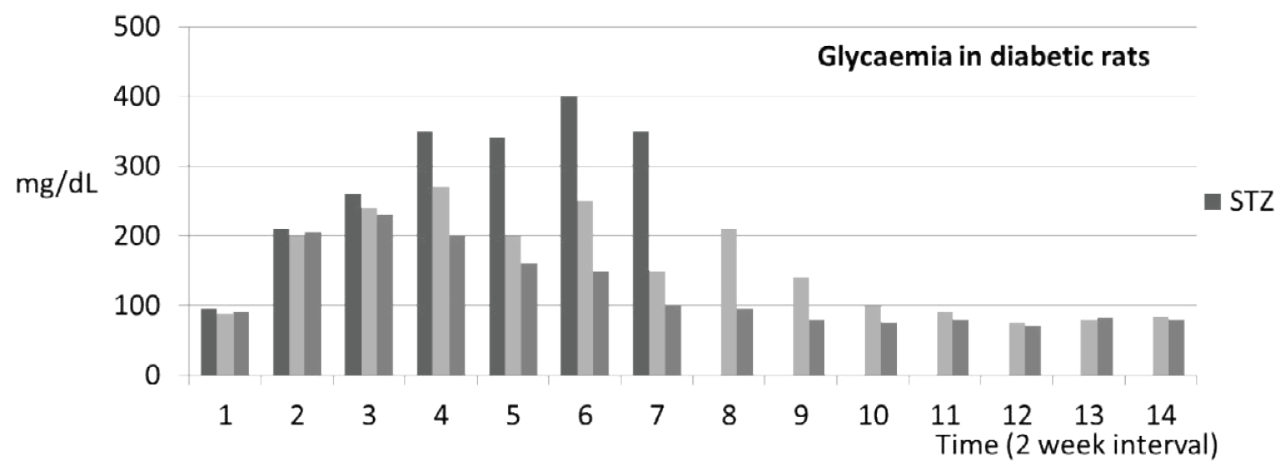

Figure 8: Histology of a fetal liver implant 4 months after operation. Well-developed hepatocyte column and bile ducts, but no connection between them and ni bile formation. (Hematoxilin eosin, $\mathrm{g} \times 40$ ). 
A.

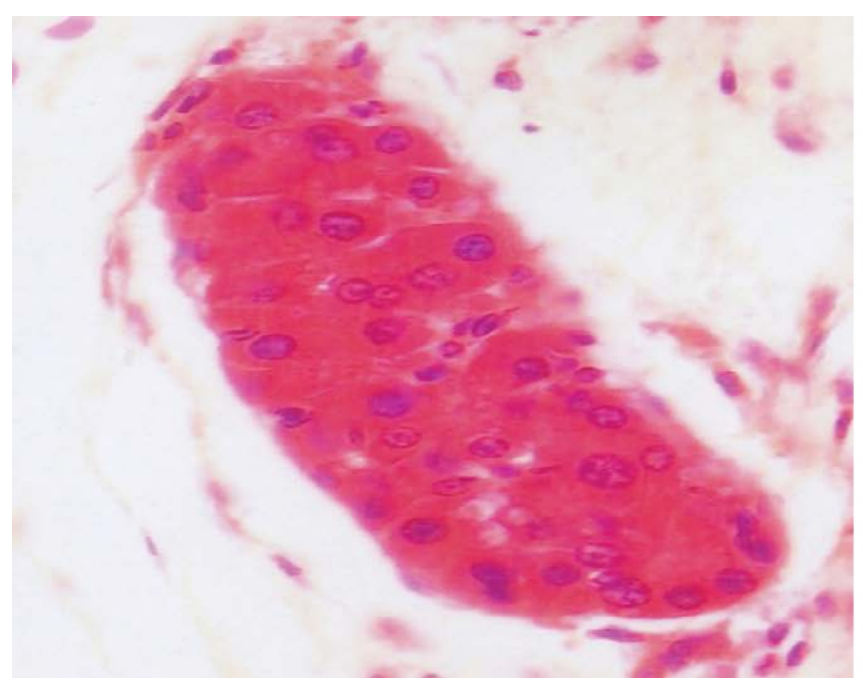

B.

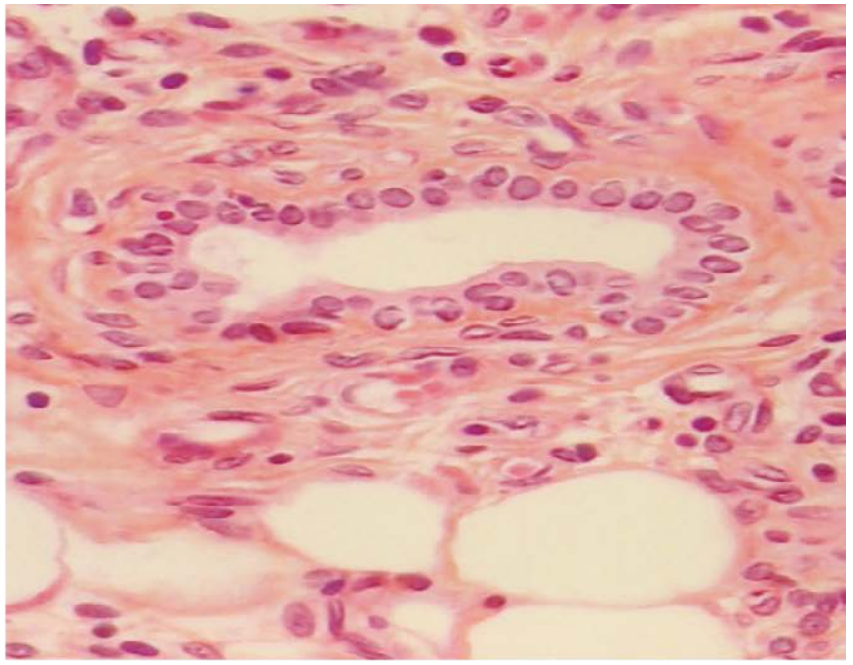

Fœtal liver implant

Figure 9: Morphology and function of fetal pancreas implants.A. Somatostatine marked cells B. glucagon marked cells, c) insulin marked cell (G $x 100)$; d) graphics of the blood glucose evolution in rats after streptozotocin injection $(75 \mathrm{mcg} / 100 \mathrm{~g} \mathrm{BW})$ : no treatment (left column) with death at week 7 ; progressive normalization of the blood glucose after grafting 4 (central column) or 8 (right column) fetal pancreas.

in operated small bowel.

All these features step by step disappear after restoration of the nervous connections of NRI or Tx intestine. But this restoration is complete only in the case of SDR, the moment of its achievement depending on the kind of provided SDR - ortho- or heterotopic.

It is to be noted that the intrinsic functional capacities of the NRI bowel - motility, secretion, adsorption and membrane digestion - remain possible, may be a little modified. The morphology of the bowel wall and even of its nervous plexus is slightly affected and only during the first days after operation, that may be attributed to the operative trauma. The local and superficial ulcerations of the mucosa observed after NRI and Tx may be explained by the alterations of the microcirculation due to the nervous disturbances [45-47].

Ischemia causes quite different, even opposite functional and morphological changes: decrease of secretion, motility palsy, apoptosis of the intramural neurons, alterations of epithelial gap junctions and other alterations [48-51]. If the duration of warm ischemia does not last more than 40-50 min, those destructions are partial and reversible. On the contrary, if ischemia overcomes this delay, the fatal so called "endotoxic" shock, well described in literature [52], develops. The sum of ischemia and NRI caused alterations is probably the cause of a slower recovery in transplanted dogs with SDR than in simply NRI+SDR cases. Besides, local intestinal ischemia caused very similar alterations to those observed in Hirschprung disease and so in certain conditions may be used as an experimental model for study, including its treatment.

So the role of CNS seems to be general direction and coordination of the organism functions and morphology. This is comforted by observations concerning bone regeneration depending on factors generated by CNS $[53,54]$, appearance of digestive disturbances in people with chronic biorhythm variations (aircraft personal), alteration of colon motility and other digestive function modifications in tetra and paraplegic patients [21], NRI of pancreato duodenal region in dogs
[55]. By the way, interruption of nervous conductivity between injured organs and CNS by so called analgesics blockade of different plexus allows not only stopping nociceptive afferent flux as pain, but also enhances the peristalsis recovery after large abdominal surgery [32]. The so-called sympathetic neurotomy around kidney arteries would leads to high blood pressure decrease in HTA [56]. In these cases, interruption of nociceptive nervous vicious loops presents a healing approach.

In relation with all above mentioned, some remarks are necessary. The first concerns some "new" models of small bowel "denervation" have been recently described [57-59]. They are rather close to our operation and the conclusions of investigations provided by their authors largely confirm our findings: disturbance of general physiological activities, maintaining of intrinsic ones as releasing of the studied molecules [6062]. Investigations concerning reinnervation of NRI or Tx small bowel also confirm that this process is never completed without exterior intervention $[45,46]$.

The second remark concerns the mechanisms of re innervation. Different authors have shown that in the case of somatic nerve regeneration, there is a complex interaction between Schwann cells and re-growing central axon through transforming growth factor beta (TGFB) activated in the distal part of the cut nerve [63]. In vegetative nervous system, the nervous fibres regeneration is enhanced either by the phenomenon of multiplication, thanks to the multiple connections of each neuron, as well as the possibility of neuron division $[64,65]$. The two mechanisms may be involved in our case and explain the relative quickness of the restoration of the NRI+SDR small bowel recovery.

In the case of fetal organ implantation interesting to note that a complete formation of morphologically and functionally competent adult-like organ was observed only when the implants have a developed intramural nervous system (intestine, stomach, and oesophagus) or a conduction system and a developed motility (heart) [66]. In the other cases - in liver and pancreas - the different parts of the organ developed 
but without connection between each other. So an endocrine activity was described, but exocrine one - not. Liver grafts are mainly used as hemopoietic agents in the treatment of leukaemia, but not as whole digestive gland $[67,68]$

An interesting question rises relatively to digestive tract grown fetal implants. We observed that during the first days after implantation a complete destructuration of the implant happens and that the organ "re-develops" after vascular reconnection with the host following ontogenetic pathway [25-27]. In the primary "porridge", no neurons could be identified. So, where they come from into the grown implant? Three possibilities may be evoked: either from the host or from the remaining precursor for nervous cells of the implant; may be also from both sources. That is an important question if a grafting may be considered for treatment of Hirschprung disease [10,11,69-71] or other degenerative alterations of the digestive tract. We can argue in favour of fetal neurons undergoing de-differentiation or/and of fetal neuron precursors having survived after the transplantation ischemic trauma, and having developed later. But it is well known that stem cells from the bone marrow circulating or injected into the blood flow are able to differentiate into neurons $[72,73]$ or in epithelial intestinal cells $[74,75]$. The same mechanism, i.e. involvement of circulating or attracted by the implant growth factors bone marrow stem cells, seems to be comforted in our experiments by the discovery of GFP positive neurons coming only from the recipient into the grafted "wild" fetal intestine. The possibility to enhance this process by inhibition of phosphodiesterase for stimulation of stem cell proliferation [76] or TGFB [63] may be of great utility for further work in the various fields of regenerative experimental and clinic medicine, including organ bio engineering of the intestine for Hirschprung and other degenerative diseases, as well as for stimulation of adult organ graft re innervation after transplantation with or without SDR (intestine, pancreas [77,78], but also lung or kidney and heart?

\section{Conclusion}

1. Interruption of nervous connections between intestine and CNS confers to the intestine a functional autonomy which alters the harmony of the digestion process regulation.

2. Spontaneous restoration of the CNS reflex influence after NRI and Tx may occur but very slowly and is rarely complete. SDR is necessary for normalization of NRI or Tx intestine physiology and morphology.

3. Alteration or destruction of the intramural nervous system leads to serious disturbances of the genuine or intrinsic intestinal function and morphology. They may be lethal, for instance after long lasting ischemia, or generate chronic irreversible disorders as in Hirschprung disease.

4. Artificial restoration of interrupted organ normal reflex links with CNS - SDR - is the only liable way to restore normal function and morphology of the transplanted bowel and the normal condition of the recipient after small bowel transplantation.

5. Intramural nervous system restoration is presently a topic of attention, and use of fetal cells or organ implantation seems to be promising for treatment of aganglionic diseases.

6. So there is a principal difference of signification between CNS and INS roles in small bowel physiology and morphology: CNS ensuring the coordination harmony and the integration of the intestinal activities within the whole organism for digestive process realization, whereas INS being capital for the very morphological existence of the intestine.

\section{Acknowledgements}

The authors express their thanks to the technicians (A.Bekkouri; $G$ van de Gucht, N.Lopez, M-C Lallemand) for their skillful help, to Mrs M.Leroy and Mr J-L Kempeneers for their precious logistic help, to professors P Bergmann, A.Gothot, lu Halperint and Academician AM Ugolev† for their scientific support.

\section{References}

1. Langley JN (1903) The autonomic nervous system. Brain 26: 1-26.

2. Bayliss WM, Starling EH (1899) The movements and innervations $f$ the small intestine. J Physiol 24: 99-143.

3. Stohr P Jr (1952) Synopsis of research results on the microscopic innervation of the gastrointestinal tract. Ergeb Anat Entwicklungsgesch 34: 250-401.

4. Pavlov IP (1893) Lectures about the work of the main digestive glands. In Complete Work Collection, Ed. Academkniga, Leningrad, 1952; T.2, book 2, 583.

5. Biddinger JE, Fox EA (2014) Reduced intestinal brain-derived neurotrophic factor increases vagal sensory innervations of the intestine and enhances satiation. J.Neurosci 34: 10379-10393.

6. Lies B, Gil V, Groneberg D, Seidler B, Saur D, et al. (2014) Interstitia cells of Cajal mediate nitrergic inhibitory neurotransmission in the murine gastrointestinal tract. Am J Physiol Gastrointest Liver Physiol 307: G98-106.

7. Sherwood L (2006) Physiologie humaine (2nd Edn.) De Boeck Ed.

8. Furness JB (2008) The Enteric Nervous System. Ed John Wiley \& Sons.

9. Scaillon M (2007) La neurogastroentérologie à l'étude des troubles de la motricité intestinale. J. de Pédiatrie Belge 9: 10-19.

10. Hotta R, Stamp LA, Foong JP, McConnell SN, Bergner AJ, et al. (2013) Transplanted progenitors generate functional enteric neurons in the postnatal colon. J Clin Invest 123: 1182-1191.

11. Bitar KN, Raghavan S, Zakhem E (2014) Tissue engineering in the gut: developments in neuromusculature. Gastroenterology 146: 1614-1624.

12. Furness JB, Callaghan BP, Rivera LR, Cho,HJ (2014) The enteric nervous system and gastrointestinal innervations: integrated local and central control. Adv Exp Med Biol 817: 39-71.

13. Lillehei RC, Manax WG, Lyons GW, Dietzman RH (1966) Transplantation of gastrointestinal organs, including small intestine and stomach. Gastroenterology 51: $936-948$

14. Adam R, Delvart V, Karam V, Ducerf C, Navarro F, et al. (2105) Compared efficacy of preserving solutions in liver transplantation. Am J Transplant 15 395-408.

15. Thøstesen LM, Qvist N, Rasmussen A Husby S (2010) Small intestine transplant for intestinal failure in children. Ugeskr Laeger 172: 883-885.

16. Ballinger W, Christy M, Ashby W (1962) Autotransplantation of the small intestine: The effect of denervation. Surgery 51: 151-155

17. Makarova LF, Shalygina NB, Maksimenkova AN, Kulik VP (1970) State of the small intestine and its intramural neural apparatus following complete severance of its connections with the central nervous system. Biull Eksp Biol Med 70: 101-105.

18. Coulic VP, Maksimenkova AN (1974) Function and morphology of the small intestine. Ed. "Nauka", Leningrad.

19. Vougas V, Vardas K, Christou C, Papadimitriou G, Florou E, et al. (2014) Intestinal neuronal dysplasia type $B$ in adults: a controversial entity. Case Rep Gastroenterol 8: 7-12.

20. Nas K, Yazmalar L, Ǎžah V, AydÄ $\pm n$ A, Ã-neÅ̈̈ K (2015) Rehabilitation of spinal cord injuries. World J Orthop 6: 8-16.

21. Stiens SA, Bergman SB, Goetz LL (1997) Neurogenic bowel dysfunction after spinal cord injury: clinical evaluation and rehabilitative management. Arch Phys Med Rehabil 78: S86-102. 
Citation: Coulic V, Mikhalsky DV, DePrez C, Delree P, lesuitova NN, et al. (2015) About the Respective Roles of Central and Intraorgan Nervous Systems in Regulation of the Gastrointestinal Tract Physiology and Morphology. Brain Disord Ther 4:172. doi:10.4172/2168-975X.1000172

Page 15 of 16

22. Wilkinson DJ, Edgar DH, Kenny SE (2012) Future therapies for Hirschsprung's disease. Semin Pediatr Surg 21: 364-370

23. Geisbauer CL, Wu BM, Dunn JC (2012) Transplantation of enteric cells into the aganglionic rodent small intestines. J Surg Res 176: 20-28.

24. Tsai YH, Murakami N, Gariepy CE (2011) Postnatal intestinal engraftment of prospectively selected enteric neural crest stem cells in a rat model of Hirschsprung disease. Neurogastroenterol Motil 23: 362-369.

25. Ferguson A, Parrott DM (1972) Growth and development of "antigen-free" grafts of foetal mouse intestine. J Pathol 106: 95-101.

26. Leapman SB, Deutsch AA, Grand RJ, Folkman J (1974) Transplantation of fetal intestine: survival and function in a subcutaneous location in adult animals. Ann Surg 179: 109-114

27. Coulic VP, DeKoster E, Delrée P, Deltenre P, DePrez C, et al. (2005) Experimental comparative evaluation of the functional capacities of ectopically grown fetal organs. Russian Journal of Physiology 91:408-430.

28. Bogach PG (1961) Mechanisms of nervous regulation of small bowel motility Kiev. Ed Ukrainian Academy of Sciences.

29. Maksimenkova AN, Kulik VP (1970) Control of the completeness of disruption and restoration of the extramural nerve connections of the small intestine following its central denervation. Biull Eksp Biol Med 69: 117-119.

30. Cannon E, Rosenbluth A (1951) Increasing of the sensitiveneness of the denervated structures. Moscow, Ed "Medgiz".

31. Bogach PG, Koval' LA, GroÄsman SD (1968) Motility of different sections of the small bowel. Fiziol Zh SSSR Im I M Sechenova 54: 90-97.

32. Camilleri M, Phillips SF (1989) Disorders of small intestinal motility Gastroenterol Clin North Am 18: 405-424.

33. SHLYGIN GK (1950) Quantitative measurement of enterokinase. Biokhimiia 15: $509-516$.

34. Shlygin GK (1952) Secretion of intestinal enzymes. Uspekhi Sovremehhoï Physiologyi 3: 14-32.

35. Shlygin GK(1964) "Main features of enzyme processes in small bowel". Vestn Acad. Nauk USSR 5:21-31.

36. Fomina LS (1953) Influence of intestinal nerves cutting on the intestinal enzyme secretion. Vopr Pitania 12: 22-25.

37. Mikhlin Sla (1955) Phosphatase contents in different organs of the digestive tract. Vopr. Med. Khimyi 1: 210-4.

38. Jacotot B (1966) La physiologie de la digestion intestinale. Gazette médicale de France $73: 837-842$

39. lesuitova NN, Timofeeva NM, Gruzdkov AA, Lessogor VM, Ugolev AM (1961) Repartition of digestion and transport functions along the intestine and mechanisms of adaptation and compensation processes. In "Actual questions of Gastroenterology" Moscow, Ed AN USSR; 2: 190-196.

40. Ugolev AM (1965) Membrane (Contact) Digestion.. Physiol Rev 45: 555-595.

41. Ugolev AM (1968) Physiology and pathology of membrane digestion. Leningrad, Springer 230

42. Yandza T, Schneider SM, Canioni D, Saint-Paul MC, Gugenheim J, et al. (2007) Intestinal transplantation. Gastroenterol Clin Biol 31: 469-479.

43. Fishbein TM (2009) Intestinal transplantation. N Engl J Med 361: 998-1008.

44. Kiyochi H, Ono A, Yamamoto N, Onnishi K, Shimahara Y, et al. (1995) Extrinsic sympathetic reinnervation after intestinal transplantation. Transplantation, 29 : 328-333.

45. Sugitani A, Reynolds JC, Tsuboi M, Todo S (1998) Extrinsic intestinal reinnervation after canine small bowel autotransplantation. Surgery 123: 2535.

46. Kulik VP, Genyk SN, Krysa VM, PidufalyÄ VR, Shevchuk VS (1981) [Microcirculatory bed of the rat small intestine after nerve reflex isolation]. Biull Eksp Biol Med 91: 654-656

47. Melikjants AG, Coulic VP, Koutcherianu VG (1980) [Reaction of intercellular contacts of the intestinal epithelium to a non-specific stress]. Gastroenterol Clin Biol 4: 265-274.
48. Coulic VP, Shalygina NB (1968) Dynamics of morphological changes in the small bowel wall after temporary exclusion of its blood supply. Eksp Khir Anesteziol 13: 17-22.

49. Linhares GK, Martins JL, Fontanezzi F, Patrício Fdos R, Montero EF (2007) Do lesions of the enteric nervous system occur following intestinal ischemia/ reperfusion? Acta Cir Bras 22: 120-124.

50. Rivera LR, Thacker M, Castelucci P, Bron R, Furness JB (2009) The reactions of specific neuron types to intestinal ischemia in the guinea pig enteric nervous system. Acta Neuropathol 118: 261-270.

51. lillehei RC, Longerbeam JK, Goott B (1961) Techniques for making autografts of the stomach, with notes on their function. Surg Forum 12: 303-305.

52. Imai S, Matsusue $Y(2002)$ Neuronal regulation of bone metabolism and anabolism: calcitonin gene-related peptide-, substance $\mathrm{P}_{-}$, and tyrosine hydroxylase-containing nerves and the bone. Microsc Res Tech 58: 61-69.

53. Ma W, Zhang X, Shi S, Zhang Y (2013) Neuropeptides stimulate human osteoblast activity and promote gap junctional intercellular communication. Neuropeptides 47: 179-186.

54. Ohtsuka T, Yokohata K, Inoue K, Nabae T, Takahata S, et al. (2002) Biliary sphincter motility after neural isolation of the pancreatoduodenal region in conscious dogs. Surgery 131: 139-148.

55. Krum H, Schlaich M, Whitbourn R, Sobotka PA, Sadowski J, et al. (2009) Catheterbased renal sympathetic denervation for resistant hypertension: a multicentre safety and proof-of-principle cohort study. Lancet 373: 1275-1281.

56. Schlaich MP, Schmieder RE, Bakris G, Blankestijn PJ, Böhm M, et al. (2013) International expert consensus statement: Percutaneous transluminal rena denervation for the treatment of resistant hypertension. J Am Coll Cardiol 62 2031-2045

57. Schlaich MP, Schmieder RE, Bakris G, Blankestijn PJ, Böhm M, et al. (2013) International expert consensus statement: Percutaneous transluminal rena denervation for the treatment of resistant hypertension. J Am Coll Cardiol 62 2031-2045

58. Kyloh M, Spencer NJ (2014) A novel anterograde neuronal racing technique to selectively label spinal afferent nerve endings that encode noxious and innoxious stimuli in viscera. Neurogastroenterol Motil $36: 440-444$

59. Santos MM, Tannuri U, Tannuri AC, Coelho MC (2009) Description of a new model of intestinal denervation and in situ ischemia-reperfusion injury using the cecal artery for perfusion. Transplant Proc 41: 3617-3621.

60. Fatima J, Houghton SG, Sarr MG (2007) Development of a simple model of extrinsic denervation of the small bowel in mouse. J Gastrointest Surg 11: 1052-1056.

61. Iqbal CW, Fatima J, Duenes J, Houghton SG, Kasparek MS, et al. (2009) Expression and function of intestinal hexoses after small intestinal denervation. Surgery; 146:100112

62. Tomita R, Fujisaki S (2008) Physiological studies on neurotensin in rat small bowe isografts. Hepatogastroenterology 55: 1360-1364.

63. Kasparek MS, Fatima J., Iqbal CW, Duenes JA, Sarr MG (2008) Effect of chronic extrinsic denervation on functional NANC innervations with vasoactive intestina polypeptide and substance $P$ in longitudinal mucles pf rat jejunum. Neurogastroenterol Motil, 20: 243-252

64. Rogister B, Delrée P, Leprince P, Martin D, Sadzot C, et al. (1993) Transforming growth factor beta as a neuronoglial signal during peripheral nervous system response to injury. J Neurosci Res 34: 32-43.

65. Ivanov IF, Radostina TN (1963) The vegetative periphery, its structure and reactive properties. Arkh Anat Gistol Embriol 45: 103-121.

66. Radostina TN (1957) "About the question of vegetative nervous system neuron multiplication". In: "Trudy I Moscow Medicine Institute"; ( 2):41-43.

67. Kulik VP, DeKoster E, Delree P, Deltenre P, DePrez K, et al. (2005) [Experimental comparative evaluation of the functional capacities of ectopically grown fetal organs] Ross Fiziol Zh Im I M Sechenova 91: 408-430.

68. Buckley RH, Whisnant KJ, Schiff RI, Gilbertsen RB, Huang AT, et al. (1976) Correction of severe combined immunodeficiency by fetal liver cells. N Engl J Med 294: 10761081.

69. Lee SW, Wang X, Chowdhury NR, Roy-Chowdhury J (2004) Hepatocyte transplantation: state of the art and strategies for overcoming existing hurdles. Ann Hepatol 3: 48-53. 
Citation: Coulic V, Mikhalsky DV, DePrez C, Delree P, lesuitova NN, et al. (2015) About the Respective Roles of Central and Intraorgan Nervous Systems in Regulation of the Gastrointestinal Tract Physiology and Morphology. Brain Disord Ther 4:172. doi:10.4172/2168-975X.1000172

70. Gershon MD (2007) Transplanting the enteric nervous system: a step closer to treatment for aganglionosis. Gut 56: 459-461.

71. Tsai YH, Murakami N, Gariepy CE (2011) Postnatal intestinal engraftment of prospectively selected enteric neural crest stem cells in a rat model of Hirschprung disease. Neurogastroenterol Motil; 23: 362-9.

72. Nakase Y, Nakamura T, Kin S, Nakashima S, Yoshikawa T, et al. (2007) Endocrine cell and nerve regeneration in autologous in situ tissue-engineered small intestine. J Surg Res 137: 61-68.

73. Mezey E, Key S, Vogelsang G, Szalayova I, Lange GD, et al. (2003) Transplanted bone marrow generates new neurons in human brains. Proc Natl Acad Sci U S A 100: 1364-1369.

74. Sostak P, Theil D, Stepp H, Roeber S, Kretzschmar HA, et al. (2007) Detection of bone marrow-derived cells expressing a neural phenotype in the human brain J Neuropathol Exp Neurol 66: 110-116.
75. Okamoto R, Yajima T, Yamazaki M, Kanai T, Mukai M, et al. (2002) Damaged epithelia regenerated by bone marrow-derived cells in the human gastrointestinal tract. Nat Med 8: 1011-1017.

76. Gao YJ, Qian W, Wang BH, Lin R, Hou XH (2006) Differentiation potential of bone marrow stromal cells to enteric neurons in vitro. Chin J Dig Dis 7: 156163

77. Santos AI, Carreira BP, Nobre RJ, Carvalho CM2, Araújo IM (2014) Stimulation of neural stem cell proliferation by inhibition of phosphodiesterase 5. Stem Cells Int 2014: 878397.

78. Mikhalski D, Coulic V, Bilibin D, Novikov V, Dlrée P (2014) Back to the reinnervation of the pancreas after transplantation? (Experimental study on dogs, cats, and rats). Transplant Proc 46: 2010-2018. 